\title{
Teacher as Unit Leader: Defining and Examining the Effects of Care and Support on Children: A Review of the Research
}

\author{
Joseph Murphy \\ Vanderbilt University, Nashville, USA \\ Email: joseph.f.murphy@vanderbilt.edu
}

Received 6 April 2016; accepted 24 September 2016; published 27 September 2016

Copyright (C) 2016 by author and Scientific Research Publishing Inc.

This work is licensed under the Creative Commons Attribution International License (CC BY).

http://creativecommons.org/licenses/by/4.0/

(c) (i) Open Access

\begin{abstract}
In this article, we integrate two distinct bodies of research to explore how teacher care and support impact student outcomes: research on relational culture in classrooms from educational scholars and, for the first time, research on positive organizational scholarship. We begin by delineating the essential elements of care and support. We then examine findings on the impact of care and support on initial (e.g., affiliation) and intermediate (e.g., engagement) mediating variables on the pathway to achievement. Since our linkage of POS to teachers and classrooms is new, we also develop a series of cautions that require attention moving forward.
\end{abstract}

\section{Keywords}

Students, Care, Support

\section{Introduction}

The purpose of this paper is to show how teacher-leader care and support work in classroom units in K-12 school organizations. Our theoretically and empirically anchored effort to do so is found in Figure 1. While the paper primarily focuses on the mediating and outcome variables, it is necessary to describe the two prosocial behaviors or the two anchoring dimensions of the model at the outset, i.e., care and support. We then turn to the mediating effects of leader care and support. We examine social integration, sense of self, and motivation. We conclude by exploring the effects of these three states on student engagement and learning. While we return to this issue in the conclusion, it is important to note that we are examining teachers as leaders in their classrooms, the first analysis to do so. 


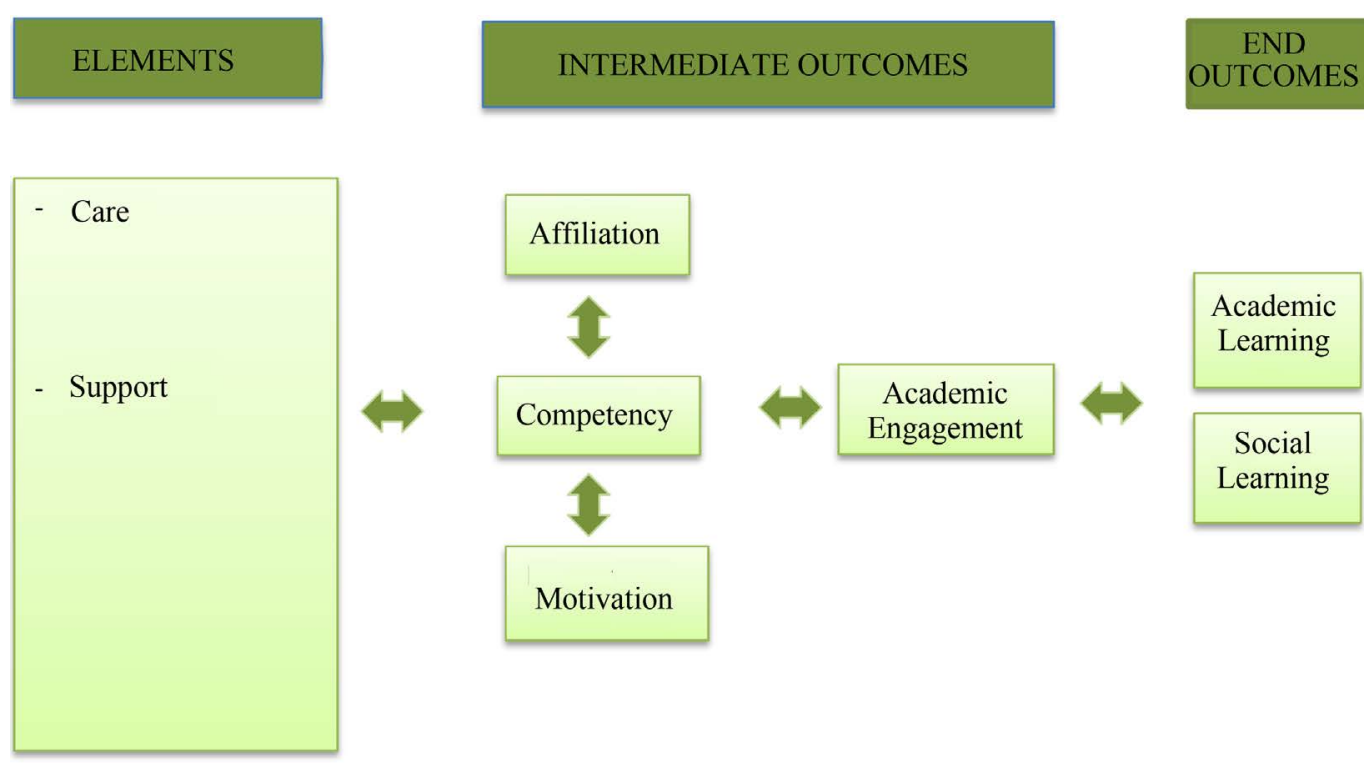

Figure 1. Learning communities for students.

\section{Care and Support}

A cardinal element of the norm of care is teachers who work to the best of their ability, who consistently bring their "A" games to the classroom - who challenge students to do their best work (Felner, Seitsinger, Brand, Burns, \& Bolton, 2007 [1]; Marks, 2000 [2]; Sanders \& Harvey, 2002 [3]). There is a significant strand of competency here (Tronto, 1993 [4], Burnier, 2003 [5]). Students also document what an instructional "A" game looks like. It includes working hard to make classes meaningful, and to show that meaningfulness to youngsters. It means classroom leaders not simply going through the motions, doing their jobs, but rather demonstrating palpable interest in whether students learn or not (Fredricks, Blumenfeld, \& Paris, 2004 [6]; Newmann, Wehlage, \& Lamburn, 1992 [7]; Wilson \& Corbett, 1999 [8]).

Another hallmark element of caring relations in schools is the willingness of teacher-leaders to reveal themselves as persons, not solely as organizational functionaries (Kroth \& Keeler, 2009 [9]). "It means the willingness to not hide your own humanness behind the manager mask” (Autry, 1991, p. 48 [10]). They do this by opening aspects of their non-professional lives to their pupils, especially incidents that are relevant to the decisions and struggles that confront youngsters (Rodriguez, 2008 [11]; Walker, 1993 [12]). That is, "the self that teachers offer is a student self rather than a career self” (Farrell, 1990 [13], p. 25). According to Caldwell \& Dixon (2009), part of this opening process is the willingness of leaders-in this case teachers-to allow themselves to be vulnerable in front of others (Adams, 2010 [14]; DePree, 1997, 2003, 2004 [15]-[17]). This stance "humanizes the teacher as a person" (Rodriguez, 2008 [11], p. 765) and helps establish a frame of authenticity for student-teacher connections (Etzioni, 1993 [18]; Raywid, 1995 [19]).

Care is also fundamentally about standards and about challenging students to meet and exceed robust expectations (Alexander \& Entwisle, 1996 [20]; Johnson \& Asera, 1999 [21]; Roth \& Brooks-Gunn, 2003 [22]). There is abundant evidence on this point: "Teachers who push students prove to be an important dimension to the personalized student-adult relationship" (Rodriguez, 2008, p. 772 [11]). Perhaps the essential point is the importance of "hard caring" (Antrop-Gonzalez \& De Jesus, 2006, p. 413 [23]) or "rugged care" (Shouse, 1996, p. 48 [24]). Challenge also means providing students with as much responsibility as they can handle (Joselowsky, 2007 [25]) and upholding a commitment to help them succeed (Walker, 1993 [12]; Wilson \& Corbett, 1999 [8]). Obstacles are acknowledged but they are not accepted as explanations for lack of performance (Rodriguez, 2008 [11]; Shouse, 1996 [24]).

A fourth dimension of caring is knowing students well (Alder, 2002 [26]), a quality Ancess (2003, p. 65 [27]) refers to as "intimacy." In a caring environment, teacher-leaders make efforts to learn about the youngsters they teach (Antrop-Gonzalez, 2006 [28]). As in other organizations, they commit the time necessary for this understanding to form and grow (Autry, 1991 [10]; Bru, Stephens, \& Torsheim, 2002 [29]). Teacher-leaders know 
what is unfolding in the lives of their students, "socially and at home. They know their students as learners in the class and in the classes of their colleagues” (Ancess, 2000, pp. 65-66 [30]). They are cognizant of the social and cultural worlds in which their pupils live Antrop-Gonzalez \& De Jesus, 2006 [23]; Case, 1997 [31]; Rodriguez, 2008 [11]).

Caring is defined also by students being valued by their teachers (Battistich, Solomon, Kim, Watson, \& Schaps, 1995 [32]; Conchas, 2001 [33]; Scheurich, 1998 [34]). According to Reitzug and Patterson (1998), this translates into leader efforts to connect with students on a personal level, rather than on a categorical basis (McLaughlin \& Talbert, 2001 [35]). More specifically, it means that each student is accepted as a person, someone who is a "valued organizational partner" (Caldwell \& Dixon, 2009, p. 97 [36]), someone who has value as an individual and as a member of communities in the school (Autry, 1991 [10]; Conchas, 2001 [33]; Rodriguez, 2008 [11]). In caring communities, being valued is conveyed through teacher-leaders being "person centered” (Hattie, 2009, p. 119 [37]). Valued status is communicated to youngsters when teachers express concern for what is happening in the world of the student and when they invest time and energy in developing and maintaining personal linkages to students (Farrell, 1990 [13]; Hattie, 2009 [37]; Wilson \& Corbett, 1999 [8]). Included here is a not-so-subtle switch from seeing them seeing them in positive terms (Avolio, Gardner, Walumbwa, Luthans, \& May, 2004 [38]; Cameron, Bright, \& Caza, 2004 [39]) and strength-based terms (Gardner, Avolio, Luthans, May, \& Walumbwa, 2005 [40])—to seeing them as “willing and capable human beings” (Reitzug \& Patterson, 1998, p. 168 [41]) who need help to address challenges in their lives. Caring leaders have positive perceptions in regards to others' capabilities (Luthans \& Avolio, 2003 [42]). In these valued relationships there is a tendency to avoid blaming youngsters when things do not go well (Patterson, Beltyukova, Berman, \& Francis, 2007 [43]).

In a related vein, caring is demonstrated when leaders take interest in and invest in their students (Croninger \& Lee, 2001 [44]; Galletta \& Ayala, 2008 [45]; Kroth \& Keeler, 2009 [9]). This includes devoting considerable personal and professional capital into one's work (McDougall, Saunders, \& Goldenberg, 2007 [46]; Strahan, 2003 [47]) and the development and honoring of reciprocal obligations (Kroth \& Keeler, 2009 [9]). It includes being accessible to students on both academic and personal fronts (Goddard, 2003 [48]; Hattie, 2009 [37]; Noguera, 1996 [49]). Investment in others tells them that they are acknowledged for who they are as persons and for their potential (DePree, 2004 [17]; Noddings, 1992 [50]; Steele, 1992 [51]). Students see "teachers as truly interested and invested in enabling [them] to succeed” (Wilson \& Corbett, 1999, p. 73 [8]). They feel that teacher-leaders are willing to provide help and personal attention (Alder, 2002 [26]; Cooper, Ponder, Merritt, \& Matthews, 2005 [52]; Rodriguez, 2008 [11]).

Caring means that leaders are accessible (Burnier, 2003 [5]; Darling-Hammond, Ancess, \& Ort, 2002 [53]; Newmann et al., 1992 [7]). A dimension of accessibility is willingness to help. Another aspect is making time available, of building closeness (Birch \& Ladd, 1997 [54]; Kroth \& Keeler, 2009 [9]) in the context of warm relationships (Opdenakker, Maulana, \& Brook, 2012 [55]; Strahan, 2003 [47]). Invitational threads are also woven into the fabric of accessibility (Ancess, 2003 [27]). So too are efforts to pull students into active participation. That is, accessibility means not exiting in the face of student resistance or oppositionality and not permitting youngsters to exit either (Newmann, 1981 [56]). The literature refers to this as maintaining beliefs in students through hardships and refusing to give up on students (Ancess, 2003 [27]; Walker, 1993 [12]). More aggressively, it is appropriate to think about accessibility in terms of advocacy for youngsters (Ancess, 2003 [27]). In strong, personalized communities, leaders stand up for students to ensure that conditions for success are forthcoming (Case, 1997 [31]; Rodriguez, 2008 [11]). Students feel that their teachers are looking out for them. They are not left to pursue success on their own or only with the help of peers (Roney, Coleman, \& Schlichting, 2007 [57]). Leaders “protect and safeguard others’ journeys” (Kroth \& Keeler, 2009, p. 514 [9]).

Another theme in the chronicle on the norm of care is constructed around the ability and willingness of leaders to see things through the eyes of others (Farrell, 1990 [13]), “to get into the other person's world” (Kroth \& Keeler, 2009, p. 508 [9]), "to comprehend someone else's world and to use that comprehension to help that individual” (Sarason, 1990, p. 169 [58]). It includes a willingness to see and understand the developmental needs of others (Tronto, 1993 [4]) and to embrace students' priorities. It means taking the world of students seriously (Csikszentmihalyi \& Larson, 1984 [59]), remembering that things that are important to students are important regardless of whether they are important to teacher-leaders or not. More importantly, it entails efforts to adapt schooling to the needs of students, not requiring students to constantly remold themselves to fit the organization (Bulkley \& Hicks, 2005 [60]; Day, 2005 [61]; Quint, 2006 [62]). This in turn requires seeing others as whole 
and in a positive light, not as defiant and damaged (Becker \& Luthar, 2002 [63]; Gardner \& Schermerhorn, 2004 [64]). "To walk in the terrain of others perceptions" (Webb, Wilson, Corbett, \& Mordecai, 1993, p. 44 [65]) requires an active responsiveness to youngsters. It means that when the norm of care is present, there is "attentive listening” (Kelsey, 1981, p. 70 [66]), that students believe that they are heard (Reitzug \& Patterson, 1998 [41]; Rodriguez, 2008 [11]). "Caring is a relational virtue" (Burton \& Dunn, 2005, p. 460 [67]) and "the ethic of care has the maintenance of relationships as a priority" (Clement, 1996, p. 11 [68]). "Relational transparency" (Avolio \& Gardner, 2005, p. 317 [69]) in the service of "mutuality and connection” (Burnier, 2003, p. 537 [5]) is highly visible. "Covenantal relationships “emerge from caring” (DePree, 2004, p. 60 [17]).

An important piece of the positive classroom storyline is teacher-leaders assessing youngsters as trustworthy (Alder, 2002 [26]; Battistich \& Hom, 1997 [70]) and students reciprocating (Adams, 2010 [14]; Antrop-Gonzalez \& DeJesus, 2006 [23]). As with other dimensions of care, we find asset-based as opposed to deficit-based assessments in our analysis of trustworthiness (Fredrickson, 2001 [71]; Gardner \& Schermerhorn, 2004 [64]); Luthans \& Church, 2002 [72]). Teachers need to earn the mantle of trustworthiness from pupils. This they do by being open, reliable, honest, benevolent, and competent in the eyes of students (Adams \& Forsyth, 2009 [73]).

Treating youngsters with respect is a tenth dimension in the web of care (Kroth \& Keeler, 2009 [9]; Vanier, 1998 [74]; Webb et al., 1993 [65]). Central points here are that teachers must give respect to receive it in return (Rodriguez, 2008 [11]). One half of the storyline here is the avoidance of actions that demean or belittle (Antrop-Gonzalez, 2006 [28]; Fredrickson, 2001 [71]). The other half of the narrative is the use of positive actions that demonstrate the fact that students are held in high regard (Raywid, 1995 [19]; Rodriguez, 2008 [11]). Treating students as young adults is important here (Ancess, 2003 [27]), with a sense of dignity (Leithwood, Jantzi, \& Steinbach, 1999 [75]). So too is the provision of opportunities for participation and voice. Actions that affirm students' cultural, racial, and ethnic backgrounds show respect (Gonzalez \& Padilla, 1997 [76]; Noguera, 1996 [49]; Scanlan \& Lopez, 2012 [77]). So too do behaviors that honor the assets students bring to the classroom more generally (Hattie, 2009 [37]).

Students possess a refined sense of equity. For that reason, care is often defined in terms of fairness or the procedural justice climate in the organization (Ehrhart, 2004 [78]), especially the perceived fairness of leaders in their treatment of those in their charge (Dirks \& Ferrin, 2002 [79]; Patterson et al., 2007 [43]). Reliability and consistency are key elements of fairness for students (Adams, 2010 [14]; Adams \& Forsyth, 2009 [73]).

Finally, recognizing the link between the learning environment and motivation (Opdenakker et al., 2012 [55]), care includes students experiencing success and opportunities to receive recognition for that success (Csikszentmihalyi \& Larson, 1984 [59]; Foster \& Hilaire, 2003 [80]; Sather, 1999 [81]). That is, leaders create a "culture of success" for students (Rodriguez, 2008, p. 776 [11]) and opportunities for acknowledgement. Newmann and his colleagues (1992, p. 22 [7]) underscore this element of care when they report that "if the school is to nurture a sense of membership, its most important task is to ensure students experience success in the development of competence."

As is the case with care, support operates on two fronts, what (Caza, Barker, and Cameron 2004, p. 169 [82]) call buffering and amplifying effects. On one hand, support buffers students from events that can damage them and their success in school (Bloomberg, Ganey, Alba, Quintero, \& Alvarez-Alcantara, 2003 [83]; Demaray \& Malecki, 2002 [84]). On the other hand, support unleashes a host of positive actions in the service of students. Support can best be thought of as the extension of help by teacher-leaders coupled with students' understanding that they can count on that assistance (Ancess, 2003 [27]; Antrop-Gonzalez \& De Jesus, 2006 [23]; Louis \& Marks, 1998 [85]). It is personalized relationships with teacher-leaders that make help seeking and the provision of assistance part of the culture (Demaray \& Malecki, 2002 [84]; Greenleaf, 1977 [86]; Tronto, 1993 [4]).

As with care, support can be defined by its essential elements, six in total. It is useful to think of these ingredients as overlapping and intertwined strands in the web of support. The first is the provision of assistance in the face of help-seeking or intuited need for such help (Adams \& Forsyth, 2009 [73]; Alder, 2002 [26]; Croninger \& Lee, 2001 [44]). Informal and formal counseling is often noted in the research here (Raywid, 1995 [19]). Navigational assistance is also discussed (Quint, 2006 [62]). So too is the provision of assistance with work (AntropGonzalez, 2006 [28]; Croninger \& Lee, 2001 [44]). Assistance in helping youngsters master transitions in life is underscored as an especially powerful (and needed) form of aid (Jackson \& Warren, 2000 [87]; Maguin \& Loeber, 1996 [88]; Rodriguez, 2008 [11]).

Support includes encouragement as well (Balfanz, Herzog, \& MacIver, 2007 [89]; Walker, 1993 [12]). Mastering school is difficult work for many students and "to invest time and energy in the present young people 
need to believe that there is a viable future” (Joselowsky, 2007, p. 272 [25]). Teacher-leaders are in a unique position to help students see the potential for success, what (Crosnoe 2011, p. 186 [90]) calls a "future orientation," when such possibilities are unclear for students (Rodriguez, 2008 [11]). Leaders can open these doors through encouragement (Newmann, 1992 [91]; Roth, Brooks-Gunn, Murray, \& Foster, 1998 [92]), especially around the importance of investments in academic work (Hoy, Hannum, \& Tschannen-Moran, 1998 [93]; Walker, 1993 [12]).

Providing safety nets is the third essential aspect of support (Cooper et al., 2005 [52]). The core idea here is to prevent students from falling through the cracks, to "go missing” and be unnoticed (Allensworth \& Easton, 2005 [94]). These protections provide another backstop against disengagement and failure (Walker, 1993 [12]). Good teacher-leaders build these nets and legitimize and encourage the use of the interventions found therein (Ancess, 2000 [30]). In supportive classrooms, teacher-leaders help students, they do not blame them for requiring assistance (Patterson et al., 2007 [43]).

Support also encompasses monitoring how well students are doing in school, socially, emotionally, and academically (Gray, Hopkins, Reynolds, Wilcox, Farrell, \& Jesson, 1999 [95]; Quint, 2006 [62]), a type of “proactive troubleshooting” (Raywid, 1995, p. 53 [19]). It includes mentoring young persons toward success, a dimension that is especially powerful for students at risk of failure (Woloszyk, 1996 [96]).

Finally, advocating is a well-illuminated strand in the web of support (Benner, 1994 [97]; Rumberger, 2011 [98]). Here, support is defined as "personally negotiating” (O’Connor, 1997, p. 616 [99]) to ensure that students garner all the aid they require to be successful, both from the school and the larger community (Cooper et al., 2005 [52]; Patterson et al., 2007 [43]; Walker, 1993 [12]). Collectively, support can be thought of as "responsibility for shepherding the student” (Balfanz et al., 2007, p. 232 [89]), shepherding made possible "as a result of direct relations with the students” (Walker, 1993, p. 72 [12]).

\section{Modeling Effects: Social Integration, Sense of Self, and Motivation}

The first links in the chain of outcomes from a culture of care and support can be seen in Figure 1. They are the most immediate outcomes of the care and support, are important, and deserve attention (Willms 2000 [100]).

\section{Social Integration}

\subsection{The Construct}

We begin with the well-established principle that "when schools become communities they fulfill a basic human need-belonging” (Bosworth \& Ferreira, 2000, p. 123 [101]). More specifically, we confirm that, as is the case with other organizations (Avolio et al., 2004 [38]), integration or "school membership is created through reciprocal relationships between the pupils and the adults representing the institution” (Kershner, 1996, p. 81 [102]). In their analysis, for example, (Roeser, Eccles, and Samaroff 2000, p. 464 [103]) found that when "adolescents perceive supportive and respectful teachers they are more likely to bond with the school." That is, "students who felt they belonged gave primary interpersonal reasons” (Nichols, 2006, p. 263 [104]). And, as researchers have consistently documented, these bondings are especially essential for students who have been placed at risk by race, ethnicity, gender, and SES (Cassidy \& Bates, 2005 [105]; Feldman \& Matjasko, 2005 [106]; Gibson, Bejinez, Hidalgo, \& Rolón, 2004 [107]; Marsh \& Kleitman, 2002 [108]). Across the literature on social integration, we are reminded of the healing power of teacher-leader linkages to children in terms of support: "Teachers and programs are in the position to restore student engagement with the school by creating an environment to which students feel bonded. A primary way to do this is by nurturing meaningful interactions between students and teachers” (Kennedy, 2011, p. 8 [109]). Smerdon 2002, p. 298 [110]) work "suggests that differences in the quality of educational experiences... are associated with significant variations in students' perceptions of membership.”

One recurring insight from the research is that all of the concepts we examine in this paper share space with each other. As we noted above, scholars across the disciplines often use the concepts synonymously (Johnson, 2009 [111]). For us, we think of membership as "being in” the community (Autry, 1991 [10]). Social integration also includes the idea of "a psychological sense of belonging” (Goodenow \& Grady, 1993, p. 66 [112]) on the part of the student. It is "a psychological need that plays a vital role in the transmission of an internalization of values and cultural norms” (Johnson, 2009, p. 101 [111]). It entails responses to group membership (Smerdon, 
$2002[110])$.

Social integration, or the sense of being integrated into the school community (Pavri \& Monda-Amaya, 2001 [113]), as described in the research includes such things as "social and personal connections to others at the school and a... belief that others in the school [are] there for them" (Goodenow \& Grady, 1993, p. 67 [112]). It represents an essential need for connections with others (Autry, 1991 [10]; McMahon et al., 2009 [114]). It includes identification with and a feeling of fitting in (Gibson et al., 2004 [107]; Willms, 2000 [100]), a sense of identification and social bonding (Kennedy, 2011 [109]; Kroeger, 2004 [115]). Connell and Wellborn 1991 [116]) add the elements of emotional security and closeness. (Cabello and Terrell 1994 [117]) layer in the idea of relatedness. Social integration is about meaningful connections that bring a psychological sense of belonging to life (Bru et al., 2002 [29]; Nieto, 1994 [118]), "the feeling of a sense of... connection to others and being part of the larger social world” (Oldfather, Thomas, Eckert, Garcia, Grannis, Kilgore, \& Tjioe, 1999, p. 287 [119]), about "solidarity and... a sense of belonging to a collective culture" (Burke \& Grosvenor, 2003, p. 70 [120]). Social integration is a sense of being part of the class unit, of being valued by the institution (Cotterell, 1992 [121]), of "feeling oneself to be an important part of the life and activity of the class" (Goodenow, 1993, p. 25 [122]). It is about affinity (Conchas, 2001 [33]), acceptance (Judson, Cohen-Dan, Leonard, Stinson, \& Colston, 2001 [123]), membership (Eckert, 1989 [124]; Gonzalez \& Padilla, 1997 [76]), belonging (Battistich et al., 1995 [32]; Fredricks et al., 2004 [6]), affiliation (Newmann, 1981 [56], O’Connor, 1997 [99]), attachment (Alexander, Entwisle, \& Horsey, 1997 [125]; Conchas, 2001 [33]), inclusion (van Dierendonck \& Patterson, 2014 [126]; Vanier, 1998 [74]), and connection (Feldman \& Matjasko, 2005 [106]; Roth \& Brooks-Gunn, 2003 [22]).

Limited care and support, on the other hand, is an invitation to weak student identification with and/or possible disaffiliation with the school, "an absence of highly developed feelings of valuing and belonging" (Voelkl, 1997, p. 296 [127]). Students in such classrooms are often portrayed as "just passing through" (Eckert, 1989, p. 65 [124]). Rather than being bonded to the school, they are independent actors, ones who often feel a sense of disconnection and alienation toward teacher-leaders (Antrop-Gonzalez, 2006 [28]; Newmann, 1981 [56]). They display what (Farrell 1990, p. 112 [13]) calls "absenting behavior," "at best a kind of passionless conformity and at worst a rejection of learning” (Sarason, 1990, p. 83 [58]). Separation and exclusion are elements of disidentification. So also are estrangement, detachment, and isolation (Newmann, 1981 [56])—“emotional and physical withdrawal” (Voelkl, 1997, p. 294 [127]).

We close this section on definition with two notes. First, children's experiences at home and in the community (Willms, 2000 [100]) and race, class, ethnicity, and sexual orientation often play a mediating role in social integration (Fine, 1986 [128]; Kosciw, Greytak, Bartkiewicz, Boesen, \& Palmer, 2012 [129]; Lee, 1999 [130]). Second, there seems to be decline in social integration through the middle school grades (Anderman, 2003 [131]), after students leave elementary school.

\subsection{Impacts of Social Integration}

Having established that social integration is a valuable organizational outcome in its own right, one shaped by care and support, we now turn to the dimensions that social integration ignite. Within the narrative underscored in the model in Figure 1, we see that social integration links to all the variables in our model, some directly and some in a mediated manner, i.e., through effects on intermediate variables. (Goodenow and Grady 1993, p. 70 [112]) make this point in the negative across all the stages of the model when they confirm "that the result of a failure to attain a full and legitimate sense of ownership in the school as a social system may be, for many students, lowered motivation, less engagement, ultimately diminished academic achievement." (Crosnoe and team 2004, p. 60 [132]), in turn, find that "social integration counterbalances these problems."

We find in the research that social integration, or meaningful connections with others, or relational co-ordination (Gittell, 2000 [133]) can promote outcomes for the organization (Dutton \& Heaphy, 2003 [134]; Miller, Grimes, McMullen, \& Vogus, 2012 [135]). Focusing on students, at the broadest level, there is capital imbedded in relationships between students and teacher-leaders (Gibson et al., 2004 [107]; McNeal, 1999 [136]). Social integration impacts students' "ability to access the benefits of human, social, and cultural capital" (McNeal, 1999 [136], p. 293; Walker, 1993 [12]), to "intergenerational bonding” (Crosnoe et al., 2004, p. 61 [132]), and to enhanced social and emotional health (Pavri \& Monda-Amaya, 2001 [113]) as well as longer-term health and well being (Willms, 2000 [110]). Social integration "plays a vital role in the transmission of values and cultural norms" (Johnson, 2009, p. 101 [111]). It "raises the costs of problem behavior" (Crosnoe et al., 2004, p. 61 
[132]). As noted throughout our discussion, social integration is especially powerful for students placed at peril by society, that is, sense of belonging is a critical element in any educational program for children placed at risk by biology, society, community, and/or family.

Identification (or disidentification) impacts commitment to the school and a sense of obligation to those at the school (Gamoran, 1996 [137]; Walker, 1993 [12]), especially teacher-leaders. Positive identification helps build a sense of legitimacy around the school and a valuing of the institution (Fredricks et al., 2004 [6]; Goodenow, 1993 [122]). According to (Voelkl 1997, p. 296 [127]), the idea of valuing schooling include[s] the recognition of the value of the school as both a social institution and a tool for facilitating personal advancement. That is, the youngster regards school as a central institution in society and feels that what is learned in class is important in its own right and that school is instrumental in obtaining his or her personal life objectives... the belief that schoolwork is both interesting and important.

Valuing also leads to a "commitment to and identification with the goals of the institution" (Eckert, 1989, p. 103 [124]); its values and purposes (Ancess, 2003 [27]; Baker, Terry, Bridger, \& Winsor, 1997 [138]; Marsh \& Kleitman, 1992 [139]); its norms and practices (Battistich et al., 1995 [32], Battistich, Solomon, Watson, \& Schaps, 1997 [140]; Voelkl, 1997 [127]); the avenues it establishes for members to pursue goals (Newmann et al., 1992 [7]), that is, its structures, policies, and practices (Hallinan \& Kubitschek, 1999 [141]); and its sanctioned outcomes (Marsh \& Kleitman, 2002 [108], Voelkl, 1997 [127]). In schools with strong care and support, youngsters become invested in the activities of the classroom (Freiberg, Huzinec, \& Templeton, 2009 [142]).

There is considerable empirical support for the conclusion that social integration in schools leads to enhanced sense of self for students (Goodenow \& Grady, 1993 [112]; Kuperminc. Leadbeater, Emmons, \& Blatt, 1997 [143]), or what (Anderman 2003, p. 6 [131]) calls "school related affect." More specifically, (McMahon and team 2009, p. 270 [114]) have established that "sense of school belonging is positively related to commitment to school goals, expectations, and academic self-efficacy." (Gibson and team 2004 [107]) add self esteem to this list of outcomes. (Murdock and Miller 2003, p. 385 [144]), in turn, show that "students' feelings of belonging predict positive school affect.” (Pavri and Monda-Amaya, 2001 [113]) confirm the connection between social integration and positive self-concept. (Goodenow and Grady, 1993 [112]) note linkages to expectancy of success.

Data from an assortment of studies reveal strong bridges between social integration and student motivation (Murdock, Anderman, \& Hodge, 2000 [145]; Oelsner, Lippold, \& Greenberg, 2011 [146]; Wilson, Karimpour, \& Rodkin, 2011 [147]), what (Anderman 2003, p. 6 [131]) labels "adaptive patterns of academic motivation” and (Goodenow and Grady 1993, p. 68 [112]) call "general school motivation.” (Gibson and team’s 2004, p. 136 [107]) conclusion that "students who fail to attain a full membership in the community are likely to be... less motivated academically" (Booker, 2006, p. 4 [148]) reinforces this point. (Goodenow and Grady 1993, p. 61 [112]) report in their review that "disconnection and diminished sense of belonging result in decreased student motivation." On the positive side of the ledger, (Goodenow and Grady 1993, p. 61 [112]) concluded that "sense of membership heavily influenced students' commitment to schooling” and (Gonzalez and Padilla 1997 [76]) discovered in their analysis what researchers have uncovered in other organizations (Wilson \& Ferch, 2005 [149]), that sense of belonging is a significant predictor of resilience.

Turning to the tail end of the model, we find that social integration has important effects on engagement (Phelan, Davidson, \& Cao, 1992 [150]; Quiroz, 2001 [151]). (Goodenow and Grady, 1993, p. 67 [112]) confirm this finding, concluding that "students who do have a high sense of belonging in school are also more likely to be academically engaged than those whose sense of belonging is low." Conceptual analysis of engagement helps us see that it includes key ideas such as alienation, delinquency, off-task behavior, attendance problems, and dropping out (Crosnoe et al., 2004 [132]; Gibson et al., 2004 [107]; Lehr, Sinclair, \& Christenson, 2004 [152]). For example, Goddard and Goff (1999, p. 47 [153]) note that "according to several theories, delinquency is related directly or indirectly, to... sense of belonging." (Gonzalez and Padilla, 1997, p. 302 [76]) confirm that "a sense of belonging may reduce students' feeling of disengagement, which may lead to dropping out." Conversely, "a student who feels a sense of belonging may become more engaged and exhibit greater effort on academic tasks" (p. 302 [76]). Lack of social integration is also linked to off-task behavior such as acting out in class (Gibson et al., 2004 [107]) or simply turning into a tourist in the classroom, someone really here in name only (RHINOS) (Flutter \& Rudduck, 2004 [154]).

Finally, we have evidence that social integration predicts academic achievement (Davis, 2003 [155]; Gibson et al., 2004 [107]; Murdock et al., 2000 [145]; Wigfield, Eccles, \& Pintrich, 1998 [156])—academic behavior (Johnson, 2009 [111]), academic performance (Booker, 2006 [148]), and academic outcomes (Gonzalez \& Pa- 
dilla, 1997 [76]) across an array of indicators, and along the way "the pursuit of task goals and the pursuit of prosocial academic and peer goals” (Davis, 2003, p. 213 [155]). That is, children who display high levels of membership exhibit increased levels of achievement (Booker, 2006 [148]) measured in terms such as student grades, minutes spent doing homework, teacher rating of competence, and standardized achievement tests (Booker, 2006 [148]; Davis, 2003 [155]; Gonzalez \& Padilla, 1997 [76]). That is, "regardless of how school bonding is conceptualized, high levels of school bonding have been consistently associated with positive youth outcomes, including academic outcomes, such as increased academic motivation, self-efficacy, and higher grade point averages" (Oelsner et., 2011, p. 465 [146]). Social integration is also linked to "positive educational trajectories" (Gibson et al., 2004, p. 138 [107]). Absence of social integration, not surprisingly, "contributes to academic problems on the individual and institutional level" (Crosnoe et al., 2004, p. 60 [132]) and deceased achievement (Booker, 2006 [148]). The summative message here is that "the evidence for the relationship between belonging and achievement is convincing even when the other school-related psychological variables are taken into account” (Booker, 2006, p. 2 [148]). We close this section with two reminders. First, as shown in Figure 1, social linkage to achievement is almost always mediated by engagement (Gibson et al., 2004 [107]). Second, the relationship between social integration and achievement is reciprocal. That is, achievement is associated with increases in engagement and then social integration (McNeely, Nonnemaker, \& Blum, 2002 [157]).

\section{Sense of Self}

\subsection{The Construct}

The challenge before us here is clear: to "pinpoint the determinants of self-concept as well as those factors that we believe the self concept, in turn, impacts" (Harter, 1990, p. 322 [158]). We begin that work in the same manner we did for social integration, with an effort to define the construct. There are a number of ideas that flow from or comprise the concept of sense of self or "psychological well-being" (Cotterell, 1992, p. 32 [121]) or psychological health. We see self esteem here, which itself is a complex concept and includes many elements (Nieto, 1994 [118]), a concept that is comprised of "distinct developmentally and ecologically keyed dimensions" (DuBois, Felner, Brand, \& Phillips, 1996, p. 569 [159]), i.e., it is shaped by biology and environment. According to Saunders, Davis, Williams, \& Williams (2004, p. 84 [160]), "self esteem refers to how individuals feel about themselves in a comprehensive or global manner." Scholars also remind us that "racial self esteem... how the individual feels about his racial group membership" (p. 84 [160]) is an important element in the domain of "student identity" (Quiroz, 2001, p. 340 [151]). So too is gender (Harter, Waters, \& Whitesell, 1997 [161]) and sexual identity (Kosciw et al., 2012 [129]; Thompson, 2004 [162]). There are "distinct and uniquely influential components of the self system" (DuBois et al., 1996, p. 544 [159]), or what we have labeled "sense of self.” We also find in the larger construct "social sense concepts, a type of expectancy belief because they contain our beliefs about ways relationships operate and our estimate about the likelihood of positive social interaction" (Davis, 2001, p. 433 [163]). Self efficacy, in turn, "is concerned with individuals" perceptions of their ability to execute a specific task (Walumbwa, Mayer, Wang, Wang, Workman, \& Christensen, 2011 [164]) — “a basic need to feel effective in their interactions with the world" (Chaplain, 1996b, p. 116 [165]), or "a belief in one's capabilities to exercise control over his or her level of functioning and environmental demands" (McMahon et al., 2009, p. $270[114])$.

The idea that is most salient in education is "academic self concept" (Shade, Kelly, \& Oberg, 1997, p. 54 [166]). "Academic self-efficacy includes how the individual feels about his/her academic capabilities" (Saunders et al., 2004, p. 85 [160]) and "the belief that students have control over their performance in a specific subject" (McMahon et al., 2009, p. 270 [114]) as well as "the extent to which students believe that with effort they can master the material they are learning in school” (Murdock \& Miller, 2003, p. 386 [144]), what (Kershner 1996 [102]) refers to as the do-ability of specific tasks. Eccles-Parsons, Adler, Futterman, Goff, Kaczala, Meece, and Midgley (1983, p. 82 [167]) label this "self-concept of ability, defined as the assortment of one's own competency to perform specific tasks or to carry out role-appropriate behaviors" and Shade and associates (1997, p. 54 [166]) describe as "whether or not students are able to handle the work school asks of them"- "adolescents perceiving themselves as academically competent and able to master school-related tasks" (Roeser et al., 2000, p. 452 [103]). Bandura (1993, p. 119 [168]) reminds us of the importance of efficacy when he notes that "a person with the same knowledge and skills may perform poorly, adequately, or extraordinarily depending on fluctuations in self-efficacy thinking." Embedded in our chronicle of self efficacy around children are the "need for 
competence” (Newmann, Rutter, \& Smith, 1989, p. 234 [169]) and “perceptions of competence” (Pintrich, 2003, p. 671 [170]), the ability "to think of themselves as competent at many things that the school demands" (Maehr \& Midgley, 1996, p. 44 [171]). Closely related to the notion of “achievement expectancies” (Johnson, 2009, p. 101 [111]) are the constructs of self confidence (Masten, Best, \& Garmezy, 1990 [172]; Rudduck, 2007 [173]) and capability (Saunders et al., 2004 [160]).

Before we proceed to review the antecedents and take up the question of the outcomes of sense of self in general and academic efficacy in particular, a few notes warrant attention. The first returns us to a theme laced throughout organizational scholarship in general and K-12 schooling in particular, the "direction of causality" (Skaalvik \& Hagtvet, 1990, p. 302 [174]). We know with some certainty that reciprocal relationships mark all the variables in our model. In this case, this means that self esteem grows from a culture of care and is influenced by social integration, and influences motivation, engagement, and performance (Stajkovic \& Luthans, 1998 [175]). We also will not be surprised to learn that a mix of school factors, family conditions, and innate intelligence appears to be essential for self-esteem during the school year (Hoge, Smit, \& Hanson, 1990 [176]). Research indicates that "the reasons why some people develop poor self-image are complex and are likely to include factors outside the school gates" (Flutter \& Rudduck, 2004, p. 120 [154]). Thus, we need to be clear that our focus is only on the school factors here, relationships between students and teacher-leaders. Third, this means that the outcomes tend to underplay major personal effects of a sense of self, effects which have been linked to troublesome conditions such as hopelessness and depression (Harter et al., 1997 [161]). Fourth, the connection between sense of self in general and academic self efficacy in particular are likely to change as a result of development (Skaalvik \& Hagtvet, 1990 [174]). Finally, we underscore "two strategies for enhancing one's self esteem. One can "reduce discrepancy by either increasing one's competence or by discounting the importance of the domain” (Harter, 1996, p. 26 [177]). Both strategies are visible in the analysis below.

\subsection{Antecedents and Outcomes}

In the introduction to the paper and in our just completed analysis of social integration we concomitantly unpacked the antecedents of sense of self. Our starting point is "that the quality of connections matters to the content and evaluation of identity” (Dutton \& Heaphy, 2003, p. 270 [134]). That scaffolding work is "strong support for [two] sources of self esteem, namely perceptions of success in areas where one has aspirations for success and the internalization of the approval (or disapproval) of significant others” (Harter, 1996, p. 25 [177]). Care and support nurtured through meaningful teacher-leader relationships are complicit in nourishing, or damaging, the intermediate variables in our model (Jackson \& Warren, 2000 [87]; Nieto, 1994 [118]), or as Davis (2003, p. 228 [155]) captures it, "student identity.” Drilling down a bit, “child-teacher relationships play an important role in developing school competence such as self esteem” (Pianta, 1999, p. 67 [178]) and understandings about ability and control (Wentzel, 2002 [179]) and "the classroom environment can be a determinant in children's beliefs about their academic self-efficacy” (Moos \& Trickett, 1987, p. 36 [180]).

In the area of culture, researchers have regularly documented that "perceived teacher caring is positively associated with... academic self efficacy” (Murdock \& Miller, 2003, p. 390 [144]) and “students” internal control beliefs" (Johnson, 2009, p. 101 [111]). There is a strong connection between felt teacher support and student self worth (Ryan, Stiller, and Lynch, 1994 [181]) as well as positive self image (Davidson \& Lang, 1960 [182]; Weinstein, 1983 [184]), self esteem (Harter, 1996 [177]), and self concept (Fine, 1986 [128])—all aspects of our larger concept, sense of self. We know that the major quest for youngsters is for personal identity (Csikszentmihalyi \& Larson, 1984 [59]; Farrell, 1990 [13]), what (Crosnoe 2011 [90]) calls identity work and (Feldman and Matjasko 2005 [106]) talk about as learning to understand oneself. Analysts also document that identity and self esteem are tightly yoked. Each student's self concept is forged in good measure through the sense of community he or she feels at school, by the relationships forged with teacher-leaders and peers (Battistich \& Hom, 1997 [70]; Guest \& Schneider, 2003 [185]; Marsh \& Kleitman, 2002 [108]). That is, students "come to an understanding of their own social worth by seeing how they are treated by others” (Crosnoe, 2011, p. 139 [90]), especially teacher-leaders. Care and support help nourish the formation of healthy self concept and stronger self esteem (Demaray \& Malecki, 2002 [84]; Pounder, 1999 [186]), thus positively shaping the nature of students’ developmental pathways (Feldman \& Matjasko, 2005 [106]) and consequently, prosocial attitudes and actions (Battistich et al., 1997 [140]; Rothman \& Cosden, 1995 [187]). Non-supportive classrooms for students, on the other hand, can lead to reduced self esteem, non-productive developmental pathways, and counter-productive at- 
titudes and behaviors (Crosnoe, 2011 [90]; Sarason, 1990 [58]). These behaviors and attitudes, in turn, are related to engagement and school success (Finn \& Rock, 1997 [188]; Mulford \& Silins, 2003 [189]; Rumberger, 2011 [98])—for better or worse.

In total then, “children's perception of their teachers' feelings toward them are correlated positively and significantly with self-perception” (Davidson \& Lang, 1960, p. 116 [182]). We also learn that the flow between support and sense of self are influenced by the students' existing assessments. For example, pre-existing assessment of self concept plays an important role (Rudduck, 2007 [173]): “The children who had a more favorable or a more adequate self concept, that is, those who achieved a higher self perception score also perceived their teachers' feelings toward them more favorably” (Davidson \& Lang, 1960, p. 109 [182]). This is important in general and particularly when we recall that there is a lowering of self-concept as one moves from elementary to middle school (Maehr \& Midgley, 1996 [171]). That is, "systematic differences exist between pre- and post-transition classrooms... These differences in classroom environment may contribute to negative changes in student beliefs” (Feldlaufer, Midgley, \& Eccles, 1988, p. 134 [190]). We also know that this flow from care and support leads to both positive and negative outcomes in sense of self (Chaplain, 1996 [165]; Dillon, 1989 [191]). Students' negative assessment of support produces negative beliefs about themselves (Harter et al., 1997 [161]), and poor academic self-concepts specifically (Murdock et al., 2000 [145]). Thus, at times, teacher-leaders are “complicit in creating negative self-esteem” (Nieto, 1994, p. 414 [118]).

Having reviewed the antecedents of sense of self, we turn to our second question: What are the outcomes of a positive or negative sense of self? We begin with the general storyline around this question and then reveal the linkages between sense of self and the other variables in the model in Figure 1. On the general front, "we highlight the importance of linking [teacher] leadership to... behaviors through mechanisms that involve the self and one's identity” (Walumbwa et al., 2011, p. 211 [164]). We discover that "efficacy beliefs contribute significantly to the level and quality of human functioning” (Bandura, 1993, p 145 [168])_-“efficacy beliefs influence how people feel, think, motivate themselves, and behave" (p. 118 [168]). They "exert a pervasive influence on personality functioning” (Caprara, Alessandri, \& Eisenberg, 2012, p. 1290 [192]) and "psychosocial functioning.” We learn that self-efficacy provides a "measure of overall well being for adolescents" (Saunders et al., 2004, p. 88 [160]), that "pupils' confidence in their abilities as learners is linked to their general level of self-esteem" (Flutter \& Rudduck, 2004, p. 120 [154]). Researchers tell us in broad strokes that sense of self is "predictive of better adult outcomes” (Garmezy, 1991, p. 426 [193]), academically-related actions in general (Eccles-Parsons et al., 1983 [167]), and task persistence specifically. "Self efficacy has been demonstrated to influence... educational achievement of children and adolescents” (Stajkovic \& Luthans, 1998, p. 256 [175]). It exerts “a powerful influence on young people’s life chances” (Rudduck, 1996, p. 139 [194]). We know that academic and emotional competence beliefs impact emotional health (Bagozzi, 2003 [195]; Roeser et al., 2000 [103]). A student's level of self efficacy is a good indicator of ability to cope with stress (Chaplain, 1996 [165] [196]). Sense of self has an "impact on the child's affective motivational and coping processes" (Harter, 1990, p. 321 [158]). That is, "beliefs about the self exert a powerful influence on interpersonal perception” (Davis, 2001, p. 433 [163]). Researchers also document a relationship between sense of self and patterns of behavior in school (Connell \& Wellborn, 1991 [116]), especially broad indices of performance (Boekaerts, 1993 [197]). This sense of self when high "functions protectively by motivating attempts at adaptation" (Masten et al., 1990, p. 431 [172]). When low, it often produces passivity, distancing oneself, and emotional distress (Fine, Torre, Burns, \& Payne, 2007 [198]; Harter et al., 1997 [161]) and “academic learned helplessness” (Eccles-Parsons et al., 1983, p. 88 [167]). "Feelings of self-efficacy increase this likelihood of instrumental behavior” (Masten et al., 1990, p. 431 [172]) and "influence what one perceives to be the opinions of others" (Harter, 1996, p. 29 [177]). Perhaps the most critical impact for children has been penned by Harter and team (1997, p. 170 [161]): "Sense of self provides a firm foundation for their transition to adulthood.”

Taking a broader sweep, we see that sense of self and self efficacy impact and are impacted in return by all the pieces of our model. Ma (2003 [199]) and Wentzel (2002 [179]) reveal the reciprocal link between students' sense of self and social integration, although the flow seems more powerful from integration to self (Anderman, 2003 [131]; McNeal, 1998 [200]). Social integration, according to McNeal (1998, p. 184 [200]) “contributes to personal development and identity formation.” Davis (2003, p. 216 [155]) uncovered a powerful effect for social integration, finding that "students' feelings of connectedness to school accounted for between $13 \%$ and $18 \%$ of the variance in ratings for emotional distress.” In their review, (McMahon and team 2009, p. 270 [114]) concluded that "sense of school belonging is positively related to commitment to school goals, expectations, and 
self-efficacy." On the other hand, "lack of a sense that one fits can have a powerful negative effect on self concept” (Rudduck, Chaplain, \& Wallace, 1996, p. 175 [201]). (Smerdon 2002, p. 289 [110]) in a seminal review found that "belonging has positive effects on academic self efficacy [and] academic self-consciousness." The takeaway message is as follows: "Belonging contributes to self efficacy" (McMahon et al., 2009, p. 278 [114]).

Sense of self is also yoked to motivation, a fact well documented in the research literature (Chaplain, 1996a [196]; Maehr \& Midgley, 1996 [171]). "Academic self-efficacy and competence perceptions motivate students... when people expect to do well, they tend to try hard, persist, and perform better” (Pintrich, 2003, p. 671 [170]). On the other hand, "people who have a low sense of efficacy... have low aspirations and weak commitment" (Bandura, 1993, p. 144 [168]). We learn that "those who have a strong belief in their capabilities exert greater effort when they fail to master the challenge” (Bandura, 1993, p. 144 [168]). Maehr and Midgley (1996, p. 42 [171]) portray the center of gravity here: "Sense of self is at the root of motivation to learn." Indeed "decades of research show that children's self perceptions, such as self efficacy... are robust mediators of motivation" (Furrer \& Skinner, 2003, p. 148 [202]).

Researchers have also established that sense of self is linked to student engagement (Connell \& Wellborn, 1991 [116]). A higher level of self esteem is associated with higher levels of both behavioral and psychological engagement (Appleton, Christensen, \& Furlong, 2008 [203]). Control of learning enhances student motivation (Rudduck \& Flutter, 2004 [204]). Students' "perceptions of self efficacy... and control are robust self system predictors of children's engagement in school” (Furrer \& Skinner, 2003, p. 151 [202]), both positively and negatively. Maehr and Midgley (1996, p. 43 [171]) underscore importance for children here when they conclude that "when something as serious as their self esteem is at stake, students do not respond thoughtfully or rationally... They are creative primarily about avoiding the kind of engagement that is necessary to learn.”

There is also abundant evidence that sense of self (i.e., self-concept ability and global self-concept) (Skaalvik \& Hargtvet, 1990 [174]) is connected to student performance in general and academic achievement specifically (Boekaerts, 1993 [197]; Roeser et al., 2000 [103]; Saunders et al., 2004 [160]), with studies and reviews of research routinely demonstrating both the positive and negative relationships between the efficacy and performance variables (Furrer \& Skinner, 2003 [202]; Saunders et al., 2004 [160]; Skaalvik \& Hargtvet, 1990 [174]). For example, (Murdock and Miller 2003, p. 394 [144]) found in their work that their "middle school students self-efficacy judgments were highly correlated with their relative classroom performance" and Eccles-Parsons and team (1983, p. 83 [167]) concluded that "studies suggest that, at least for some students, increases in self confidence can produce increases in achievement." Eccles goes on to tell us that by adolescence, expectancies are tightly linked to general achievement performance. Bandura (1993, p. 133 [168]) helps us see that "students who have a low sense of efficacy to manage academic demands are especially vulnerable to achievement anxiety.” Skaalvik and Hagtvet (1990, pp. 304 and 206 [174]) have weighed in on the directionality of the relationship here, reporting that, in general, "self concept of ability is a stronger predictor of academic achievement than vice versa [or]... self concept has causal predominance over achievement for high school students." And Bandura (1993, p. 137 [168]) takes us inside the avenue of influence here, reporting that "increased sense of academic efficacy promotes academic attainment both directly and by heightening aspirations." A few studies provide evidence on the aspects of achievement influenced. For example, in (Roeser and team's 2000, p. 456 [103]) work, "all of those students who achieved good grades also reported a sense of competency and efficacy in the academic domain.” And high levels of academic efficacy, control, and self esteem are related to achievements in life (Silverstein \& Krate, 1975 [205]).

\section{Motivation}

\subsection{The Construct}

The final proximal outcome in our model in a general sense is students' attitudes or dispositions toward school. The center of gravity here is student motivation. As we examine in some detail below, the impact of culture is mediated by motivational variables (Owens \& Hekman, 2012 [206]). More specifically, a culture of care and support is "associated with certain motivational cognitions that collectively appear to be related to performance" (Maehr \& Fyans, 1989, p. 233 [207]). Or, using our nomenclature, "the enactment of the ethic of care" (Kropiewnicki \& Shapiro, 2001, p. 24 [208]) nurtures positive attitudes toward school (Birch \& Ladd, 1997 [54]). Motivation itself "results from some combination of the likelihood that one will achieve a goal (expectancy) and how much that goal is desired or wanted (valued)" (Graham, Taylor, \& Hudley, 1998, p. 608 [209]). That is, 
"the definition of motivation involves the combination of the probability of goal attainment and the value associated with the goal” (Booker, 2006, p. 5 [148]). Pintrich and DeGroot (1990, p. 34 [210]) report that when these two conditions are in place, high probability and "beliefs that the task is interesting and important, students will engage in more metacognitive activity, more cognitive strategy use, and more effective effort management.”

When we look into the essential components of motivation (Wigfield et al., 1998 [156]), three elements are visible, interest (meaningfulness), values, and goals (Pintrich, 2003 [170]). The goal of motivation theory is to explain "what gets individuals moving (energization) and toward what activities (direction)” (Pintrich, 2003, p. 669 [170]). Our transition point here is "that motivation of students is a critical component in the learning process” (Maehr \& Fyans, 1989, p. 216 [207]); “interests, values, and goals mediate students’ performance, choices, and efforts” (Wigfield et al., 1998, p. 104 [156]); and goals and interests are essential to understanding why students act as they do (Pintrich, 2003 [170]; Wentzel, 1998 [211]).

Analysts in the area of motivation provide helpful insights on motivation beyond definitional material. To begin with, we are reminded that there are two types of motivation, intrinsic and extrinsic. As noted earlier, we also know that intrinsic motivation declines over the school career of children (Harter, 1996 [177]; Wallace, 1996 [208] [209]), particularly as students make the move to junior high school (Harter, 1996 [177]; Pintrich, 2003 [170]). Maehr and Midgley (1996, p. 94 [171]) find that this decline "can be part attributed to what is going on in the schools and classrooms... The psychological environment of the learning environment... is responsible for the kinds of motivation problems that are too readily evident.” Feldlaufer and associates (1988, p. 134 [190]) help us see how teacher-leaders impact what unfolds inside classrooms.

In general, there is limited evidence suggesting that junior high school classrooms, in comparison to elementary school classrooms, offer fewer opportunities for student self-management and choice, and are characterized by a less positive teacher/student relationship, both of which could undermine students' interest in their academic subjects. In addition, there is some evidence that the shift to junior high school is associated with an increase in whole class task organization, between-classroom ability grouping, and external evaluation; practices that may increase the saliency of social comparison and ability self-assessment. This may have negative effects on some students' confidence in their ability and motivation to achieve; in particular those students who are not highly able or do not perceive themselves as highly able prior to entry into junior high school.

This turn of events is unfortunate for "there is compelling evidence that students who are more intrinsically than extrinsically motivated fare better” (Brewster \& Fager, 2000, p. 18 [214]).

Third, we learn that belief systems formed early in life can be antithetical to achievement. Given our analysis to date, we discover that these non-supportive belief systems are associated with children's social and economic hardships, especially students of color and boys. Fourth, we also know that "the investment made by pupils is highly individualized and related to their perceptions of an imagined future painted by their teachers" (Wallace, 1996b, p. 61 [213]). Children "come to view the learning environment as taking this or that form and presenting certain possibilities that are grasped by the student and that relate to the ways he will (or will not) invest" (Maehr \& Midgley, 1996, p. 67 [171]). Fifth, as noted earlier in general, there is a reciprocal relationship between motivation and the other variables in our model (e.g., Figure 1). For example, motivation is both influenced by and an influencer of sense of self and motivation is connected to engagement and achievement, factors that exert an influence on motivation (Murdock et al., 2000 [145]).

\subsection{The Elements of Motivation}

We reported above that the definition of motivation highlights three concepts-interest, values, and goals. Here we provide a snapshot of each of the pieces. Interest has been well described by (Oldfather and team 1999, p. 282 [119]) as “a continuing impulse to learn." These scholars tell us that interest "is characterized by intense involvement, curiosity, and a search for understanding” (p. 283 [119]). Maehr and Midgley (1996, p. 28 [171]) add to our understanding here.

The point, of course, is that we are all regularly confronted with multiple options, and we do in fact go in some directions and avoid others. This directionality of our behavior over the short and long terms is specifically embraced in the term personal investment. We participate, engage, invest in some activities and acts and not in others. Personal investment infers that an individual does one thing when other possibilities 
are presumably open to him.

Analysts explain that "taking personal responsibility for their problems in school and life" (Penna \& Tallerico, 2005, p. 14 [215]) can be considered an aspect of student interest (Kershner, 1996 [102]). So too, relatedly, is sense of obligation. This sense of obligation, scholars conclude "appears to make a difference in what students do; it appears to predictably mediate certain relationships between the person and the environment” (Willems, 1967, p. 1258 [216]).

The second "family of social-cognitive constructs that has been a major focus of research on student motivations is goals and goal orientation” (Pintrich, 2003, p. 675 [170]), what Wentzel, (2002, p. 291 [179]) “calls mastery goal orientation.” It can be described as educational aspirations (Murdock et al., 2000 [145]), what youngsters see themselves attempting to accomplish (Wentzel, 2002 [179]). It links to student effort and investment (Wentzel, 2002 [179]). Indeed, Appleton and team (2008, p. 378 [203]) report that "investment in education is believed to largely be a function of students' perceptions of task or ability goals.”

As was the case with interest, we know that social contexts impact goal adoption (Maehr \& Midgley, 1996 [171]). Maehr and Midgley go on to report "that goal-adoption is to a significant degree a function of experienced contexts and that the psychological character of these contexts can be changed to affect goal adoption patterns.” We close here by acknowledging "that students' perceptions of task and ability goal emphases in the classroom are in fact related to qualitatively different motivational orientations and patterns” (Maehr \& Midgley, 1996, p. 90 [171]).

Finally, we add values to the motivation basket, a construct that blends quite easily with interest and goals. "Unlike achievement-related cognitions which largely center on beliefs about ability, values have to do with desires and preferences... and are more directly concerned with the perceived importance, attractiveness, or usefulness of achievement activities” (Graham et al., 1998, p. 606 [209]). Eccles and associates (1983, p. 31 [167]) define value as follows: "The overall value of any specific task is a function of three major components: 1) the attainment value of the task, 2) the intrinsic or interest value of the task, and 3) the utility of the task for future goals.” Davis (2001, p. 434 [163]) deepens the narrative, explaining that "perceived importance refers to the extent to which performance on a task confirms a central aspect of one's self-schema [see earlier section on sense of self]. Perceived utility refers to the usefulness of the task for attaining future goals. Intrinsic interest refers to the amount of pleasure associated with a task.” Eccles-Parsons and team (1983, p. 89 [167]) outline two components of goals: “intrinsic or interest value and utility value." The former "is the inherent, immediate enjoyment one gets from engaging in an activity” (p. 89 [167]). In some scales it is assessed by measuring students' interest and their perceived importance of coursework (Murdock \& Miller, 2003 [144]). The latter “is determined by the importance of the task for some future goal that might be somewhat unrelated to the process nature of the task at hand" (Eccles-Parsons et al., 1983, pp. 89-90 [167]). (Murdock and team 2000 [145]) present the two ideas of concrete and abstract values. According to Davis (2001, p. 434 [163]), findings in the field "indicate value plays a crucial role in guiding students' choice of achievement activities.” In sum, researchers show us, "the value of a particular task to a particular person is a function of both the perceived qualities of the task and the individual's needs, goals, and self perceptions” (Eccles et al., 1983, p. 90 [167]). As was the case with other aspects of motivation, values are implicated in the underperformance of Black and ethnic minority youngsters. Because some "African American students feel that their efforts to achieve academically will not result in increased economic or social mobility, they opt to devalue the importance of schooling... African American students expect little from school, so they value little in school” (Booker, 2006, p. 5 [148]).

\subsection{Influences and Impacts}

We start with the evidence, from general to specific, that teacher-leader care and support leads to student motivation. We do so first by highlighting major conclusions: 1) school actions can and do affect a student's level of motivation (Brewster \& Fager, 2000 [214]); 2) motivation develops from a complex web of social and personal relationships (Goodenow \& Grady, 1993 [112]), that is, "the general quality of the relational environment is a relevant variable” (Birch \& Ladd, 1997, p. 76 [54]); 3) within schooling, the connection that forms between a student and teacher-leader can be a robust motivator (Davis, 2001 [163]). Indeed "teachers can have a much greater influence on students’ motivation displayed in their classrooms than can parents” (Wentzel, 2002, p. 297 [179]); and 4) youngsters who report stronger connections with their teachers are more motivated in school (Murdock \& Miller, 2003 [144]), and relatedly “the psychological environment of the learning environment in 
classrooms and schools is responsible for motivational problems” (Maehr \& Midgley, 1996, p. 94 [171]).

Research confirms "that the way in which students perceive school culture is related to their motives" (Maehr \& Midgley, 1996, p. 72 [171]) and that "teacher support is independently related to numerous motivational variables” (Murdock \& Miller, 2003, p. 385 [144]): that is, "supportive relationships with teachers... promote students motivation to learn" (Davis, 2001, p. 432 [163]). Teacher-leader use of targeted caregiving strategies (Wentzel, 2002 [179]) helps account for student motivation. We know from studies that "students who experience their teachers as autonomy supportive and warm are more likely to be intrinsically motivated" (Ryan et al., 1994, p. 231 [181]). Researchers inform us that "motivation is enhanced in classrooms with teachers who foster the experience of relatedness to socializing others" (p. 226 [181]) and who create "psychological environments of small groups" (Maehr \& Fyans, 1989, p. 234 [207]). Teachers characterized by students "as less caring, warm, friendly, and supportive have a negative impact on motivation” (Feldlaufer et al., 1998, p. 151 [190]). So too do teachers who emphasize control-oriented assessment (Bru et al., 2002 [29]). Finally, a "mismatch between students' desires and classroom opportunities will result in a decline in motivation" (Eccles et al., 1993, p. 566 [217]).

Attending to the essential elements of motivation—interests, goals, and values_adds nuance to the impact of a caring and supportive culture via teacher/leader-student relationships. Maehr and Midgley (1996, p. 67 [171]) start us on our voyage here by reminding us that "culture consists of perceptions... that are useful in defining when and how children will invest in learning." A supportive and caring teacher-leader is also linked to increased interest in school and in subject areas (Davis, 2001 [163]; Wigfield et al., 1998 [156]). "Feelings of relatedness tapped by measures of school climate and quality of teacher-student relationships... has been linked to interest in school” (Furrer \& Skinner, 2003, p. 149 [202]). So too are activities that are more open (Wigfield et al., 1998 [156]). On the other hand, "students who perceived math classrooms as putting greater constraints on their preferred level of participation in classroom decision-making... showed the largest and most consistent declines in their interest in math between the sixth and seventh grade” (Eccles et al., 1993, p. 566 [217]). Classroom environments "that overlooked or negated students' needs and devalued their voices... created apathy toward learning” (Rodriguez, 2008, p. 776 [11]).

Along with interest, scholars document that school climate in general (Maehr \& Midgley, 1996 [171]) and students' views of teacher-leader caring in particular (Johnson, 2009 [111])) make an important "difference in the bottom line of education which is the investment of students in learning" (Maehr \& Midgley, 1996, p. 100 [171]). In places "where students believe their voices matter they are more likely to be invested" (Quaglia \& Corso, 2014, p. 3 [218]).

Moving to the second element of motivation, "schools and classrooms have been shown to vary in how they lead individuals to construe... the goals of a situation" (Maehr \& Midgley, 1996, p. 48 [171]) and in "their achievement goal pursuit" (Davis, 2001, p. 448 [163]). "The point... is that school culture is likely to significantly shape the individual goals students come to hold” (Maehr \& Midgley, 1996, p. 66 [171]). Equally important, we learn from analyses of motivation that youngsters' assessments of general levels of care and support from teachers define these social contexts (Wentzel, 2002 [179]) and that "students with greater feelings of support from teachers are more likely to adopt prosocial goals” (Nichols, 2006, p. 256 [104]). Finally, we find that a caring and supportive culture increase the value students attribute to their learning (Murdock \& Miller, 2003 [144]). The overall theme here is "that students' perceived task values differ as a result of teachers' instructional practices and support” (Anderman, 2003, p. 8 [131]). Overall, the research reveals that perceived teacher-leader support is a powerful predictor of values (Murdock \& Miller, 2002 [145]; Pavri \& Monda-Amaya, $2001[113])$.

Further assessment of motivation confirms that interests, goals, and values influence the two other psychological states in the model in Figure 1. "In this regard, motivation is related to underlying psychological processes" (Appleton et al., 2008, p. 379 [203]). Turning first to sense of self, we discern that "higher levels of perceived control are positively related to motivation" (Pintrich, 2003, p. 673 [170]) and that "personal goal setting is influenced by self-appraisal capabilities. The stronger the perceived self-efficacy, the higher the goal challenge" (Bandura, 1993,, p. 118 [168]). "Students who believe they are able and that they can do well are much more likely to be motivated” (Pintrich, 2003, p. 671 [170]).

Social integration exposes similar influences (Anderman, 2003 [131]; Rudduck, 2007 [173]). That is, "psychological connections to school play an important role in affecting student motivation" (Appleton et al., 2008, p. 377 [203]). Or as Ryan and team (1994, p. 226 [181]) express it, "in virtually every domain of human endea- 
vor there is mounting evidence that a network of supportive relationships facilitates an individual's motivation.' Belongingness or social integration mediates between teacher/leader-student relationships and motivation" (Epstein, 1981 [215] [216]; Nichols, 2006 [104]). A “student cannot progress to a subsequent stage of growth and knowledge without feeling a sense of belonging and acceptance from those in the immediate environment" (Booker, 2006, p. 5 [148]). “To summarize, longitudinal analyses reveal a pattern of continuing, significant, independent influence of opportunities for participation on students’ attitudes toward school” (Epstein, 1981, p. 99 [220]). That is, belonging promotes positive dispositions toward school or belonging predicts motivation (Nichols, 2006 [104]). We also learn that the positive effects of participation or attitudes are ongoing and cumulative (Epstein, 1981 [220]).

At the general level, high levels of motivation, as a psychological state, translate into greater effort (Piccolo, Greenbaum, Hartog, \& Folger, 2010, p. 265 [221]). At the school level, we find that there is a "robust relationship between cognitive engagement and investment in learning” (p. 381) and that students are more likely to be engaged when they have internalized a value for learning. Indeed, these internalized values are essential to student engagement (Wigfield et al., 1998 [156]). Although, again we are confronted with the matter of causality, "it appears that the students who choose to become cognitively engaged... are those who are interested in and value the tasks they work on in classrooms” (Pintrich \& DeGroot, 1990, p. 37 [210]), i.e., they are motivated.

We also see that motivation powers achievement (Roeser, Midgley, \& Urdan, 1996 [222]; Rudduck \& Flutter, 2004 [204]). “There is a mutual concurrent effect of attitudes and classroom success” (Epstein, 1981 b, p. 103 [220]), one that occurs “indirectly and over time” (Epstein, 1981b, p. 103 [220]). Maehr and Fyans (1989, p. 216 [207]) report that studies "have suggested that motivation accounts for between $16 \%$ - $20 \%$ of the variation in student achievement." Later research concluded that "motivation accounted for up to 38\% of the student achievement variance” (Maehr \& Fyans, 1989, p. 216 [207]). Indeed, "there is a large literature that identifies... motivation beliefs as critical in understanding students' academic outcomes” (Ryan, 2000, p. 102 [223]). That is, "motivation is the key, producing social, cognitive, and academic outcomes” (Wigfield et al., 1998, p. 91 [156]). Analysts have established linkages between the elements of motivation and academic achievement, including standardized test scores (Maehr \& Midgley, 1996 [171]): "Perceived culture is associated with certain motivational cognitions that collectively appear to be related to performance [and] the motivational components are linked in important ways to student cognitive engagement and academic performance in the classroom” (Pintrich \& DeGroot, 1990, p. 37 [210]).

On one front, we see a connection between interest and learning. In his work, for example, Wentzel (2002, p. 295 [179]) found that "interest in school was related significantly and positively to academic performance." (Smerdon 2002, p. 289 [110]) confirms that students' "commitment to academic work... is a key factor in explaining and enhancing students’ academic success,” including grades and test scores (Wentzel, 1998 [211]). Goals also influence learning and achievement for students (Pintrich, 2003 [170]). Finally, there is a documented connection between student values and learning: That is, "there is a positive relationship between students’ valuing of school and school outcomes” (Quiroz, 2001, p. 340 [151]), one extending to students' future economic well-being. Researchers conclude that the values in the motivation formula often are "prerequisite to academic learning” (Hamilton, 1983, p. 323 [224]) and securing a good education (Roeser et al., 2000 [103]). On the other hand, there is a strong linkage between "devaluing the importance of schooling... and lower academic performance” (Booker, 2006, p. 5. [148]).

\subsection{The State of Engagement}

We begin here with the argument that engagement is the door into important outcomes (May, Gilson, \& Harter, 2004 [225]). That is, “engagement is a basic human need mediating the relationship between the environment and performance” (Harter, Schmidt, \& Keyes, 2003, p. 211 [226]). We agree with (Connell and Wellborn 1991 [116]) that the analysis of engagement in schools needs to be highlighted more forcefully than it has in the past. To strengthen schools, it is essential, therefore, that increasing student engagement be relocated to the center stage of the school improvement production (Datnow, Park, \& Kennedy, 2008 [227]; Joselowsky, 2007 [25]) and that we work to deepen our understanding of this pivotal construct (Fredricks et al., 2004 [6]; Marks, 2000 [2]). One important step would "be to expand the priorities of schools to include engagement in learning as a central institutional goal along with meeting certain performance standards” (Connell \& Wellborn, 1991, p. 70 [116]). Positive teacher leadership and productive teacher-student relationships (Gardner et al., 2005 [40]; May- 
er, Kuenzi, Greenbaum, Bardes, \& Salvador, 2009 [228]) nurture engagement and offset the dynamics that promote disengagement (Johnson, 2009 [111]; Willms, 2000 [100]). “Teachers’ behaviors in the classroom continue to impact the level of engagement with class material” (Davis, 2003, p. 211 [155]) or as Rodriguez (2008, p. 768 [11]) encapsulates the message: "respectful relationships can significantly mediate academic engagement or disengagement.” That is, “engagement is a result of interaction between students, teachers, and the curriculum” (Taylor-Dunlop \& Norton, 1997, p. 278 [229]). Qualities that “emerge within the relationship between students and teachers prove to be important not only for students’ academic engagement... but also for students social and emotional development” (Kennedy, 2011, p. 8 [109]). On the disengagement theme, (Murdock and team 2000, p. 329 [145]) conclude that "student-teacher relationships may be the key to understanding the process of alienation from schooling." More specifically, "studies of high school dropouts document poor relationships with teachers and perceived teacher disrespect/unfairness as central to students' decision to leave school” (Murdock et al., 2000, p. 329 [145]). "Students who feel unconnected... find it harder to become constructively involved in academic activities... and should be more likely to be disaffected” (Furrer \& Skinner, 2003, p. 149 [202]). Researchers who investigate the workings of student engagement and disengagement in classrooms find that disengagement builds up over time and can become so severe that it leads to dropping out of school (Davis, 2003 [155]).

\subsection{The Construct}

There are a variety of ways to build understanding of engagement in classroom organizations. A good way to begin is to examine definitions of the concept, acknowledging that there is some fuzziness across the various studies (Dahl, 1995 [230]; Marks, 2000 [2]). Furrer and Skinner (2003, p. 149 [202]) report that

Engagement refers to active, goal-directed, flexible, constructive, persistent, focused interactions with the social and physical environment. In contrast patterns of disaffection, in which individuals are alienated, apathetic, rebellious, frightened, or burned out, turn people away from opportunities for learning.

Newmann (1989, p. 34 [231]) provides the following definition.

Engagement is more than motivation of the general desire to succeed in school. It involves participation, connection, attachment, and integration in particular settings and tasks. As such, engagement is the opposite of alienation: isolation, separation, detachment, and fragmentation. Persons are engaged to a greater or lesser degree with particular other people, tasks, objects, or organizations. Thus, engagement helps to activate underlying motivation and can also generate new motivation. Engagement in academic work is the student's psychological investment in learning, comprehending, and mastering knowledge or skills. Students' level of engagement in academic work can be inferred from the way they complete academic tasks: the amount of time they spend, the intensity of their concentration, the enthusiasm they express, and the degree of care they show.

And Balfanz and team (2007, p. 224 [89]) “define school disengagement as a higher order factor composed of correlated subfactors measuring different aspects of the process of detaching from school, disconnecting from its norms and expectations, reducing effort and involvement at school, and withdrawing from a commitment to school and to school completion.” Wallace (1999, p. 52 [212]) reminds us engagement "goes beyond compliance to denote a level of emotional involvement in school work." "Engagement requires intention, concentration, and commitment by students” (Taylor-Dunlop \& Norton, 1997, p. 278 [229]), “attendance, participation, attention, and behavior” (Kennedy, 2011, p. 7 [109]).

Another way to peer into engagement is to review the components of this "meta construct" (Appleton et al., 2008, p. 381 [203]). We understand, to begin with, that engagement is a multi-faceted concept (Li, Lynch, Kalvin, Liu, \& Lerner, 2011 [232]; Wallace, 1996 [212]). Fredricks and associates 2004 [6]) provide us with the richest conceptual map of engagement, one that is scaffolded on three core pillars: cognitive engagement, emotional engagement, and behavioral engagement. Cognitive engagement attends to issues of self regulation. The focus here is on metacognition and cognitive strategy use and investment in learning. It "includes flexibility in problem solving, preference for hard work, and positive coping in the face of failure” (p. 64 [6]). Emotional engagement according to these scholars is often cast in terms of student identification with school, including an assortment of "emotions related to the school, schoolwork, and the people at the school” (p. 66 [6]). Finally, for 
Fredricks and colleagues (2004 [6]) and other scholars of student engagement (Alexander et al., 1997 [125]; Balfanz et al., 2007 [89]; Voelkl, 1997 [127]), behavioral engagement includes general and specific actions, including work-related and conduct actions such as putting forth effort, attending, participating, paying attention, and demonstrating persistence. More specifically, they define behavioral engagement in three ways.

The first definition entails positive conduct, such as following the rules and adhering to classroom norms, as well as the absence of disruptive behaviors such as skipping school and getting in trouble. The second definition concerns involvement in learning and academic tasks and includes behaviors such as effort, persistence, concentration, attention, asking questions, and contributing to class discussion. A third definition involves participation in school-related activities such as athletics or school governance. (Fredricks et al., 2004, p. 61 [6]).

We start with the fact that engagement and disengagement are two sides of a continuum (May et al., 2004 [225]; Newmann et al., 1992 [7]). The job of teacher-leader is to get and keep students at the farthest right-hand side of that continuum, full and meaningful engagement in the classroom and the school, "arranging conditions so that people expend energy in ways that enhance engagement with work” (Newmann, 1981, p. 548 [56]). As suggested above, the roots of disengagement (or engagement) in classroom organizations can be traced to conditions in the larger world of childhood and adolescence, to the alignment between this larger world and the focus and methods of schooling, and to actions specific to classrooms. At times, schools cause disengagement (Sarason, 1990 [58]). More often than not, however, they fail to ameliorate or exacerbate nascent disaffiliation (Baker et al., 1997 [138]), either by ignoring the realities of the larger world in which youngsters operate or ineptly (often thoughtlessly) attempting to force students to fit into prevailing school models (e.g., demonstrating unawareness of or rejecting cultural norms and values of working class and minority cultures) (Crosnoe, 2011 [90]; O’Connor, 1997 [99]).

It is also instructive to see what is inside these components and to examine how they are measured. Appleton and colleagues (2008, p. 372 [203]) provide considerable knowledge here when they explain that

Variables such as time on task, credits earned toward graduation, and homework completion represent indicators of academic engagement, whereas attendance, suspensions, voluntary classroom participation, and extracurricular participation represent indicators of behavioral engagement. Cognitive and psychological engagement are considered less observable and gauged with more internal indicators, including self-regulation, relevance of schoolwork to future endeavors, value of learning, personal goals and autonomy as indicators of cognitive engagement and feelings of identification or belonging, and relationships with teachers and peers as indicators of psychological engagement.

Other scholars point to strategies such as reports of engagement and disengagement by teacher-leaders and/or students (Connell \& Wellborn, 1991 [116]). Still other analysts note the specific tools used to generate reports such as questionnaires, student writing assignment, and logs of participation and involvement (Furrer \& Skinner, 2003 [202]; Lodge, 2005 [233]).

Relatedly, understanding is enhanced by identifying the indicators assessed in the quest to corral the components of engagement (or disengagement) in schools. One indicator is "graduation from high school with sufficient academic and social skills to partake in postsecondary enrollment options and/or the world of work" (Appleton et al., 2008, p. 372 [203]). Ryan (2000, p. 102 [223]) adds "participation in classes and time on homework” to the list (Kohl, 1994 [234]). (Connell and Wellborn 1991, p. 54 [116]) provide a number of other indicators of student engagement, including on task vs. off-task behavior, tardiness, and classes skipped. (Burke and Grosvenor 2003 [120]) add truancy and Willms (2000 [100]) adds frequency of absence, class-skipping, and late arrival to school. Newmann (1989, p. 34 [231]) deepens our list of indicators, reporting that "levels of engagement in academic work can be inferred from the way they [students] complete academic tasks: the amount of time they spend, the intensity of their concentration, the enthusiasm they express, and the degree of care they show."

\subsection{Antecedents}

Not surprisingly, we find a robust mediated connection between leadership and engagement (Owens \& Hekman, 2012 [206]). We also see that positive school cultures are reflected through student-teacher/leader relationships 
and school engagement (Moos \& Moos, 1978 [235]). The overall storyline is that these powerful relations promote "vital engagement" while the absence of these ingredients leads to disengagement (Gardner et al., 2005, p. 366 [40]). Fredricks and team (2004, p. 83 [6]) provide the anchoring statement here when they remind us that "engagement can result from a variety of antecedents in the context, both social and academic."

When we examine the cultural support dimension of classrooms, we uncover powerful effects on student engagement (Rudduck \& Flutter, 2004 [204]). That is, "students in schools with more elements of communal organization show higher engagement and greater gains in engagement over time” (Fredricks et al., 2004, p. 73 [6]). Positive culture, i.e., care and support, or positive school psychology (Bryk, Sebring, Allensworth, Luppescu, \& Easton, 2010 [236]) for youngsters is shown to be a central catalyst in fostering student engagement, especially for students from lower SES families (Felner et al., 2007 [1]; Ma \& Klinger, 2000 [237]; Rumberger, 2011 [98]). That is, the quality of student relationships with teacher-leaders is "significantly associated with active engagement in schools" (Goodenow, 1993, p. 23 [122]), "school culture that prioritizes relationships can significantly mediate academic engagement” (Rodriguez, 2008, p. 768 [11]). We see at the center of the train of logic that "engagement with a task... is contingently related to personal and social relationships" (Wallace, 1996b, p. 53 [213]). When "the conditions of learning are experienced as congenial then students are more likely to commit themselves to learning” (Rudduck \& Flutter, 2004, p. 133 [204]). That is, "relatedness is something that influences engagement” (Wigfield et al., 1998, p. 76 [156]).

Researchers confirm a strong positive linkage between care and engagement (Baker et al., 1997 [138]; Quint, 2006 [62]). They also substantiate an association between students' perceptions of teacher-leader support and active investment and involvement in the classroom and school (Battistich et al., 1995 [32]; Conchas, 2001 [33]), with all three types of involvement we presented earlier, cognitive, emotional and behavioral (Balfanz et al., 2007 [89]; DeMaray \& Malecki, 2002a, 2002b [84] [238]). Finally, an abundance of research draws empirical links between membership and engagement (Fredricks et al., 2004 [6]; Goodenow, 1993 [122]) as reflected in investment and participation (Ma, 2003 [199]; Osterman, 2000 [239]).

Delving into care, we find that a number of elements have important implications for engagement. In (Johnson's 2009, p. 101 [111]) review, we learn that "teacher caring accounted for $47 \%$ of the variance in student engagement among high school junior and seniors in a middle income suburban community.” We would expect the number to be even larger in lower-SES communities (Quiroz, 2001 [151]; Stanton-Salazar, 1997 [240]). (Davis, 2003, p. 211 [155]) confirms that "teachers' level of involvement with their students (both actual and perceived by the students) influenced quality of students' behavioral and emotional engagement in school.” Research uncovers voice and agency linked to student engagement as well (Morgan \& Streb, 2001 [241]; Smyth, 2006 [242]). "Students articulated how overlooking or negating students' needs and devaluing their voices... produced disengagement from school and created apathy toward learning” (Rodriguez, 2008, p. 776 [11]). Being valued and being respected also are linked empirically to engagement (Kohl, 1994 [234]; McLean-Donaldson, 1994 [243]). Indeed for “many students respect precedes engagement” (Rodriguez, 2008, p. 767 [11]). “If pupils feel that they matter in a school and that they are respected they are more likely to commit themselves to the school's purposes” (Rudduck \& Flutter, 2004, p. 133 [204]). That is, "students are more likely to engage in classroom activities if they feel supported and valued” (Wentzel, 1997, p. 417 [244]). For students from varied ethnicities and races, valuing is often conveyed in cultural appreciation (McLean-Donaldson, 1994 [243]; Tyson, 2002 [245]). For example, in the (McLean-Donaldson work 1994, p. 27 [243]) "students of color were very often resentful of unequal treatment and tended to internalize this mistreatment by withdrawing their interest in classes... They also felt cheated and disrespected, because they were aware that their cultural groups made major contributions to the United States but were still ignored in the curricula." Warmth is implicated in the engagement/disengagement narrative as well (Goldstein, 1999 [246]). So too are student assessments of fairness (or equal treatment) by teacher-leaders (Nichols, 2006 [104]). For example, (Murdock and colleagues 2000, p. 329 [145]) inform us that "studies of high school dropouts document... perceived teacher disrespect/unfairness as central to students' decisions to leave school.”

In parallel fashion researchers document the robust role of teacher-leader support in enhancing engagement and preventing disengagement (Davis, 2003 [155]; Kosciw et al., 2012 [129]), what Ryan and team (1994, p. 237 [181]) refer to as "the real-world importance of students underlying beliefs that teachers represent sources of interpersonal support.” Powerfully, Appleton and team (2008, p. 374 [203]) conclude that “engaged students perceive more support from teachers and peers and that this perception leads to a beneficial cycle of increased levels of engagement and increased adult support.” Open communication is one of the elements inside the do- 
main of support that has been empirically linked to engagement (Birch \& Ladd, 1997 [54]). So too are strategies that support students in the augmentation of social capital (Stanton-Salazar, 1997 [240]). Academic support is another piece of the narrative that prevents disengaged student actions (Bru et al., 2002 [29]). (Wallace 1996b, p. 34 [213]) adds that “'engagement' is best sustained... in a supportive and interesting cultural environment," that is, "students feel supported when teachers take the time to create environments that are culturally relevant and meaningful places for learners." On the other hand, "attempts to 'monoculture”" (Nieto, 1994, p. 402 [118]) have been surfaced as a cause of student disengagement via dropping out (Wilson \& Corbett, 2001 [247]). Continuing with our eyes on the negative aspects of support, analysts have determined that classrooms "low in teacher support tend to have higher rates of student absenteeism” (Moos \& Moos, 1978, p. 265 [235]). Similarly, (Quiroz 2001 [151]) and Stanton-Salazar (1997 [240]) report that antagonistic or apathetic actions by teacherleaders can lead to "the institutionalization of detachment" (p. 7).

A nearly identical theme is evident with the three intermediate outcomes in Figure 1. Each of the three mediating variables can enrich or diminish engagement. Sense of self in terms of "self esteem and academic self efficacy" (Saunders et al., 2004, p. 86 [160]) is associated with "intentions to complete the school year" (p. 86) for example. We also know "that students who value self-respect exhibit (statistically) significantly lower frequency on delinquent behavior" (Ma, 2003, p. 341 [199]). Pintrich and DeGroot (1990, p. 37 [210]) also tell us "that self-respect plays a facilitative role in cognitive engagement." "Confident students will be more cognitively engaged in learning and thinking than students who doubt their capabilities to do well" (Pintrich, 2003, p. 671 [170]). Self-concept as reflected in measures of competence (Fredricks et al., 2004 [6]), "student appraisals of personal skillfulness" (Laffey, 1982, p. 62 [248]), and agency is powerfully linked with student engagement. In a similar fashion, motivation is linked to classroom engagement (Hattie, 2009 [37]; Opdenakker et al., 2012 [55]). "Students who are more motivated to learn the material (not just get good grades)... are more cognitively engaged in trying to learn and comprehend the material” (Pintrich \& DeGroot, 1990, p. 37 [210]). (Pintrich and DeGroot 1990, p. 37 [210]) argue that a focus on "intrinsic value for schoolwork... may lead to more cognitive engagement in the day-to-day work of the classroom.” (Appleton and team 2008 [203]) reach a similar conclusion on student identification.

Other scholars have uncovered powerful connections between social integration and student engagement (Gonzalez \& Padilla, 1997 [76]); Newmann, 1992 [91]; Voelkl, 1997 [127]).

Turning to social integration, (Gibson and team 2004, p. 129 [107]) tell us that "research points... to a strong and positive link between students' subjective sense of belonging in school and their participation... Quite simply students function better and participate more in school settings and situations when they feel they belong." (McMahon and team 2009, p. 270 [114]) carry us a bit further, concluding that "students who feel greater school belonging are likely more motivated to attend school and to put forth greater effort because of external choice." More specifically still, (Mahoney and Cairne's 1997 [249]) results indicate that social integration decreases early school dropout. This is especially the case for those students most at risk. "Students who report greater perceptions of belonging are less likely to be absent from school” as well (Nichols, 2006, p. 257 [104]). Social integration defined as greater opportunities to be involved in school decision making provides an avenue to engage youngsters in the school community (Mitra \& Gross, 2009 [250]).

On the downside, we learn that "many students do not feel accepted by their classmates or teachers. Gradually these students withdraw from school life and become disaffected from school” (Willms, 2000, p. 3 [100]). We also discover that in "contexts where students experience feelings of rejection or alienation, their participation declines" (Gibson et al., 2004, p. 129 [107]). (Ma 2003, p. 340 [199]) informs us that research "indicates that sense of belonging is a direct cause of dropping out of high school.” Such disengagement, disaffection, and/or alienation from school often has quite negative consequences (Richert, 1994 [251]), including rejection of the moral worth of the classroom organization (Stinchcombe, 1964 [252]); disruption in class and "exerting negative influence on other students” (Willms, 2000, p. 3 [100]); gang-connected problems (Ma, 2003 [199]); dropping out of school (Patterson et al., 2007 [43]); bullying (Chaplain 1996a [196]); and student resistance (Dillon, 1989 [191]), such as “maintaining a noisy and extrovert disdain for [school] work" (Rudduck \& Flutter, 2004, p. 69 [204]).

\subsection{Outcomes of Engagement}

We have learned over the years that engagement is a "teaching indicator" (Harter et al., 2003, p. 220 [226]) for 
important distal outcomes both in organizations in general and in classrooms in particular (Connell \& Welborn, 1991 [116]; Pintrich \& DeGroot, 1990 [210]), such as individual well-being and organizational performance (Gardner et al., 2005 [40]). e.g., engagement generates higher frequency of positive affect: (Harter et al., 2003, p. 2 [226]), work-related performance (Stajkovic \& Luthans, 1998 [175]), and positive social behavior. On a broad front, engagement is always a necessity for acquiring knowledge and skills (Wallace, 1996 [212]). The starting message in classrooms is that to improve achievement teachers need to first learn how to engage students (Levin, 2000 [253]). In their research, (Connell and Wellborn 1991, p. 59 [116]) uncovered “direct relations between positive and negative aspects of perceived competence [and] student engagement support.”

A comparison of scores from the pupil self-concept of learner scale for the engaged and disengaged pupils showed that the scores of the disengaged pupils were significantly lower on every aspect of the scale. The disengaged pupils felt that they had greater difficulty in particular with task orientation and with more abstract problem solving tasks. They were more likely to experience difficulties with writing, coping with tests and doing homework. They were less likely to feel good about their school work. The disengaged pupils also indicated that they had a tendency to give up more easily in school work, to do things without thinking, to make mistakes because they didn’t listen, and to give up if they didn’t understand something. (Chaplain, 1996a, p. 106 [196]).

While researchers routinely have confirmed the conclusion that there is a strong relationship between participation and achievement, Appleton and colleagues (2008, p. 374 [203]) also find that there are "larger differences at higher levels of participation than at lower levels." Not surprisingly then, engagement is a powerful "predictor of children's long-term academic achievement and their eventual completion of school” (Furrer \& Skinner, 2003, p. 149 [202]). For example, (Saunders and associates 2004 p. 82 [160]) disclose that "when academic disengagement begins in elementary school, it is more difficult for young men to be well prepared for more challenging high school curriculums, putting them at risk for further failure and dropout." The summative message is "that classroom specific effort and engagement are related significantly to academic performance" (Wentzel, 1998, p. 203 [211]). That is, "engaged students tend to earn higher grades, perform better on tests, and drop out at lower rates, while lower levels of engagement place students at risk for negative outcomes" (Appleton et al., 2008, p. 383 [203]).

\subsection{Academic and Social Learning}

Throughout this paper, we have driven home three critical points from the research. First, student-teacher/leader relationships are the center of gravity for the effective schools universe. Second, these relations play out through a culture of care and support. Third, support and care power up a series of intermediate variables (i.e., sense of self, social integration, and motivation) that deepen student engagement which, in turn, pushes social and academic outcomes upward, i.e., "without care, learning cannot occur” (Richert, 1994 [251]). This script is both parsimonious and powerful. In this section, we take on one more assignment, a review with the lens focused specifically on the outcome vector of the script just reviewed. To start, we make clear that the academic outcomes fall into the last box in our model (see Figure 1). While the direction of the flow of influence in our model is dominant, reciprocity is evident as well, e.g., motivation influences engagement and engagement influences motivation. For example, (Tyson 2002, p. 1184 [245]) informs us that his study "suggests that... achievement outcomes play a central role in the development of attitudes toward school” and Appleton and associates (2008, p. 376 [203]) find that "previous achievement bolsters future levels of identification.” We also want to underscore the fact that researchers have assessed a variety of outcomes that extend beyond student academic and social learning, to benefits for teacher-leaders and the larger organization (Rudduck, 2007 [173]). Included here is the fact that productive culture within the bond of positive teacher/leader-student relationships can help teachers grow and enrich the craft and success of their teaching. For example, "it is abundantly clear... that pupils can offer their teachers much thoughtful, constructive and helpful commentary on life and learning in their classrooms” (Arnot, McIntyre, Pedder, \& Reay, 2004, p. 88 [254]). They bring their teachers understanding (Bragg, 2007 [255]; Fielding, 2004 [256] [257]), the grist for the formation of classrooms as learning communities (Lodge, 2005 [233]; Rodriguez, 2008 [11]), including "the collective knowledge that emerges from a group sharing experiences and understanding the social influences that affect individual lives” (Wallerstein \& Bernstein, 1988, p. 381 [258]). Positive teacher/leader-student relationships are also at the heart of the creation 
of "healthy organizations" (Frost, 2003, p. 10 [259]).

Turning the lens back to students and moving beyond the confines of academic achievement and school social learning (e.g., student satisfaction, commitment to life-long learning), we discover that care and support "make help seeking easier" (Rodriguez, 2008, p. 766 [11]). They often "open doors and provide the resources required for academic success" (Gibson et al., 2004, p. 131 [107]). Student wellbeing also may be enhanced by fostering a school environment of support (McNeely et al., 2002 [158]). Care and support can enhance the meaningfulness of schooling for youngsters (Hamilton, 1983 [224]) as well as promote a sense of specialness (Dillon, 1989 [191]). Action and climate in the type of classroom organizations we have portrayed herein are associated with "more favorable reactions to school life" (Epstein, 1981b, p. 106 [220]). Students tend to feel "happier and more secure... in innovation oriented, structured affiliation oriented and supportive oriented classes" (Moos, 1978, p. 61 [260]). Students are "more satisfied and higher on well being in less structured classes emphasizing teacher-student and student-student support” (Moos, 1979, p. 188 [261]). In his study, for example, (Moos 1979, p. 190 [261]) found that "the classroom climate block explained... 20 to 25 percent of the predictable variance in students sense of well being and satisfaction with learning." In short, there is "strong support for the general hypothesis that the differences in classroom environments are systematically related to different student satisfactions" (Trickett \& Moos, 1974, p. 7 [262]). Analysts also reveal that the effects of the full model include "a disposition to life-long learning" (Willms, 2000, p. 3 [100]). Care and support "gives pupils the knowledge and skills necessary for taking an active role in a democratic society in later life" (Flutter \& Rudduck, 2004, p. 18 [154]). Finally, researchers find "compelling evidence" that care and support inside healthy student-teacher/ leader relationships are related to longer-term outcomes as well. Support is connected to health and well-being (Harter et al., 2003 [226]) and "contributes to the quality of life of youths” (Willms, 2000, p. 86 [100]), now and in the future (Miron \& Lauria, 1998 [263]). On the latter point, for example, we know that "through relationships with institutional agents, a segment of society gains the resources, privileges, and support necessary to advance and maintain their economic and political position in society” (Stanton-Salazar, 1997, p. 6 [240]). It is also hypothesized that students ensconced in relationships of care and support "will subsequently be engaged in their work environments [while] extreme disaffection from the school and truancy in particular are associated with marital problems, violence, adult criminality and incarceration” (Willms, 2000, p. 56 [100]). And while it is only lightly treated in the educational research, there is some sense that all the outcomes associated with support grow the longer students are in such environments (Epstein, 1981 [219]).

Returning specifically to the impacts of care and support, presented below is a summary of what we have reported so far. In the largest sense, we know that students crave meaningful relationships (Marquez-Zenkov, 2007 [264]). We know that these "relationships mediate learning” (Davis, 2003, p. 222 [156]). We understand that "relationships with teachers can have a profound effect on student learning and growth" (Kennedy, 2011, p. 9 [109]). "Teacher-child closeness" (Birch \& Ladd, 1997, p. 61 [54]) and connection with teacher-leaders are related to academic and social outcomes (Davis, 2001 [163]). (Pianta 1999, p. 12 [178]) taps this nicely when he tells us that "in both risk and nonrisk samples, a focus on enhancing child-teacher relationships can be expected to elevate competency levels and help attenuate the rates of failure currently present in public schools." (Howard 2001, p. 134 [265]) adds the following on the consequences of relationships: "lack of personal teacher-student relationships as reflected in a lack of caring and overall teacher apathy were contributing factors to school failure." In general, we know that caring has "positive organizational effects" (Kroth \& Keeler, 2009, p. 513 [9]), enhances resilience (Wilson \& Ferch, 2005 [149]), commitment (Fehr \& Gelfand, 2012 [266]; Leroy, Polanski \& Simons, 2012 [267]) and citizenship behaviors (Peterson, Galvin, \& Lange, 2012 [268]) and "collective processes” (Lawrence \& Maitlis, 2012, p. 658 [269]), trust (Gardner et al., 2005 [40]), and morale (Lawrence \& Maitlis, 2012 [269]). In particular, we know that "child-teacher relationships play an important role in developing skills in the areas of peer relations, emotional development, and self regulation; in competencies such as problem solving and self esteem" (Pianta, 1999, p. 67 [178]); in "effective growth" (Walberg \& Anderson, 1968, p. 417 [270]); in engagement in school (Rodriguez, 2008 [11]); in students' "social and emotional functioning" (Roeser et al., 2000, p. 447 [103]); in academic effort (Howard, 2002 [271]; Johnson, 2009 [111]); and in achievement (Davis, 2003 [155]; Kennedy, 2011 [109]). We also have seen that "cognitive and social development are severely affected by extremely adverse environments" (Masten et al., 1990, 435 [172]) and the resulting "dysfunctional attributes" that can take hold of the organization (Cameron et al., 2004, p. 777 [39]) and dysfunctional conflicts that take hold in relationships (Ferch \& Mitchell, 2001 [272]).

Without revisiting already covered findings, we conclude that, "it is noteworthy that overall school culture... 
is associated with students' motivational orientation, which in turn was related to performance on standardized measures of achievement in major instructional domains” (Maehr \& Midgley, 1996, p. 96 [171]). Or more succinctly, "children's perceptions of teacher support and caring have been related to a range of... student outcomes" (Pianta, 1999, p. 93 [178]). Or more succinctly still, "perceived quality of school climate is linked to academic performance" (Kuperminc et al., 1997. p. 76 [143]). It is the "psychological characteristics" that matter most (Maehr \& Fyans, 1989, p. 243 [207]). Scholarly analyses have arrived at similar conclusions about the effect of school climate on math and reading grades (Wright \& Cowen, 1982 [273]) and "different kinds of cognitive growth" (Walberg \& Anderson, 1968, p. 417 [270]). Looking at the indicators developed, we see evidence of effects across a range of empirical studies and scholarly reviews. Respect, encouragement, and support in general are highlighted in these analyses (Booker, 2006 [148]; Rodriguez, 2008 [11]). So too is ownership (Wigfield et al., 1998 [156]) and voice (Arnot et al., 2004 [254]; Mitra \& Gross, 2009 [250]). We discover also that "cultural and linguistic incorporation in the school curriculum is a significant predictor of academic success as measured by standardized tests of reading” (Zanger, 1993, p. 178 [274]). Warmth inside supportive relationships also is linked significantly to achievement (Booker, 2006 [148]). The takeaway message is that in general there is a significant effect between leadership and organizational performance (Frost, 2003 [259]; Harter et al., 2003 [226]; Peterson et al., 2012 [268]; Mayer, Aquino, Greenbaum, \& Kuenzi, 2012 [275]; Walumbwa, Avolio, Gardner, Wernsing, \& Peterson, 2008 [276]), there is a "causal chain leading from school culture... to achievement” (Maehr \& Fyans, 1989, p. 233 [207]).

\section{Discussion}

\subsection{Caveats and Cautions}

Before we close, some cautions merit attention. First, few studies track the full course of teacher-leader care and support from relationships to intermediate outcomes (e.g., motivation), to engagement, to learning. While we construct this chain below (see Figure 1), it is important to remember that we bundled together studies that examine single couplings (e.g., engagement to achievement) as we developed our analysis.

Second, there is some overlap with the concept we explore here. And there is overlap between our understanding of caring leadership and other practice-framed descriptions of leadership (e.g., authentic leadership, virtuous leadership) (Lennick \& Kiel, 2007 [277]; Lilius, Worline, Maitlis, Kanov, Dutton, \& Frost, 2008 [278]; Mayer et al., 2012 [275]). On one level this is inevitable as forms of leadership and their defining elements overlap in the research. On a second level, it may have a unifying effect, for as (Nussbaum 1996, p. 29 [279]) reminds us "on the whole the philosophical tradition is in such vigorous conversation that these terms are frequently used as translations of one another and are thus pulled toward one another in meaning."

Third, our chronicle attends to the general picture, a reality that established "boundary conditions" for our work (Dutton, Worline, Frost, \& Lilius, 2006, p. 38 [280]). Sub-narratives that are "unique to sites and tend to grade level, subject matter, location, and background of participants" (Alvermann, Young, Weaver, Hinchman, Moore, Phelps, \& Zalewski, 1996, p. 265 [281]) are not examined in any detail. This choice, while necessary, compromises the "ability to understand the nuances of individual contexts" (p. 265).

Fourth, we see here only one dynamic in the explanatory framework of student outcomes, student-teacher relationships focused on the cultural sphere of classrooms. Many other issues, both in school and externally (Rauner, 2000 [282]) influence the outcomes in our model. Relational coordination among teacher-leaders is important but is not examined herein (Gittell, 2000 [133], 2003 [183]). More critically, the instructional actions of teacher-leaders are only indirectly treated here. The effects here depend on the goals and preferences of the children (Moos \& David, 1981 [283]) and student background (Moos \& Moos, 1978 [235]). We also know that "students' views of the larger economic world may predict their behavior related to schools" (Murdock et al., 2000, p. 346 [145]). So too, students "willingness to work in class depends on the students' cognitive image of the classroom in which his work yields future rewards" (Stinchcombe, 1964, p. 19 [252]). Peers are powerfully linked to care and support (Li et al., 2011 [232]). Parent-child relationships also shape students' relationships with peers and teachers (Connell \& Wellborn, 1991 [116]). The size of the school (Midgley, Feldlaufer, \& Eccles, 1989 [284]) and the characteristics of the school do so as well (Willms, 2000 [100]). "The larger psychological environment of the school is not an irrelevant variable” either (Maehr \& Fyans, 1989, p. 244 [207]). (Crosnoe and associates 2004, p. 71 [132]) portray this larger storyline here by reminding us that "research recognizes the value of approaching social issues at the intersection of interpersonal and institutional contexts. In- 
dividual behavior is closely related to personal relationships, but such relationships are dependent, in part, on the institutions in which they take place.”

Fifth, for purposes of analysis we primarily follow the links of the chain in Figure 1 from left to right (e.g., motivation to engagement). It is essential to note, however, that energy between the links flows in both directions (e.g., engagement to performance). That is, we know that "the interplay between social variables within the context of schooling almost certainly is reciprocal in nature” (Anderman, 2003, p. 8 [131]). Outcomes can be precursors and precursors can be outcomes in our model (Anderman, 2003 [131]; Piccolo et al., 2010 [221]). More specifically, as an example, "positive self-concept may be both a contributor to and a result of successful school achievement” (Silverstein \& Krate, 1975, p. 209 [205]).

Sixth, the very notion of connected linkages tells us that the pathway from leader support to learning is indirect (Avolio et al., 2004 [38]). You cannot go from support directly to performance (Maehr \& Fyans, 1989 [207]). There are mediating links along the voyage. Seventh, as we have noted above "contextual moderators" (Mayer et al., 2009, p. 11 [228]) and boundary conditions are important (Podsakoff, Whiting, Podsakoff, \& Blume, 2009 [285]). See (Johns, 2006 [286] for a comprehensive review of context.) For example, analysts tell us that "students' reactions are systematically affected by length of time in participating environments" (Epstein, 1981b, p. 96 [219]), especially extended time in negative environments in which "expressive alienation” (Stinchcombe, 1964, p. 49 [252]) has accumulated (Larkin, 1979 [287]; Murdock et al., 2000 [145]), where a "schoolalienated life-style among children” is pervasive (Silverstein \& Krate, 1975, p. 23 [205]). These researchers also inform us that context includes the ethnicity of children (Maehr \& Fyans, 1989 [207]), "expected occupational destinies” (Stanton-Salazar, 1997, p. 15 [240]), student age (Lehr et al., 2004 [152]), and socio-economic conditions (Willms, 2000 [100])—for example, working class minority students who are "not competent cultural decoders within mainstream institutions including the school” (Stanton-Salazar, 1997, p. 25 [240]).

Seventh, our work is focused on explanations, showing what is, and on opening pathways of improvement. However, "the practice of care is complex" (Tronto, 1993, p. 124 [4] and as Maehr and Midgley (1996, p. 125 [171]) reminds us, improvement "will not happen automatically. Even knowing what to do does not ensure that something will be done.”

Eight, while we do not have the space to examine it here, it is important to acknowledge the difficulties of creating care and support as well as the potential dark side of caring (See Grimshaw, 1986 [288]), a concern that requires special attention in schools because of the "presumption of virtue” (Greenleaf, 1977, p. 182 [86]) and significant power differentials between classroom leaders and the students being led (Kelsey, 1981 [66], Sernak, 1998 [289]). More concretely (Sernak, 1998, p. 18 [289]) warns us that "nurturing an ethic of caring within structures that are bureaucratic and hierarchial [can] be a daunting task,” i.e., often problematic (Rynes, Bartunke, Dutton, \& Margolis, 2012 [290]). The possibility of "the ethic of care becoming simply another tool to maintain a rule-bound bureaucratic organizational structure” is quite real. We note here the warning of Carl (Rogers 1961, p. 45 [291]) of the dangers “manufactured relationships”: and of Owens and Hekman (2012 [206]) on the dangers of false behaviors. Looking outward, we also learn of a problematic state of affairs: "care has little status in our society” (Tronto, 1993, p. 122 [4]). "Care is devalued and those who do caring work are devalued" (p. 114).

Finally, we also acknowledge that there are "inherent risks and costs" that can accompany "the enactment of an ethic of care" Lawrence \& Maitlis, 2012, p. 66 [269]). Seen here is the fact that "care involves conflict” (Trronto, 1993, p. 10 [4]) and care makes individuals vulnerable (Regan \& Brooks, 1995 [292]; Rynes et al., 2012 [290]; Senge, 1997 [293]), and can lead to burn out (Wuthnow, 1991 [294]). To care is to be open and "to be open is an enormously risky enterprise” (Vanier, 1998, p. 79 [74]). Particularly relevant here also is the possibility of subversion of a didactic concept moved to the organizational level (Liedtka, 1996 [295]; Madden, Duchon, Madden, \& Plowman, 2012 [296])—taking care for rather than taking care of (Sernak, 2004 [297]) the danger of moving from relationships to transactions (Liedtka, 1996 [295]), and to seeing people as objects (Caldwell \& Dixon, 2009 [36]; Rogers, 1961 [291]). In particular, “caring in its ethical sense cannot be grafted onto organizations. Caring is difficult today in rule-based hierarchies because they are not designed to foster care” (Liedtka, 1996, p. 192 [295]), they impede care in organizations in general and schools in particular (Marshall, Patterson, Rogers, \& Steels, 1996 [298]; Sernak, 1998 [289]).

\subsection{Contributions}

This is the first work to employ the frame of "teacher as unit leader," a perspective we find in other organiza- 
tions, that is as a leader of her or his own classroom. Teachers, in the organizational literature have nearly universally been treated as workers impacted by higher-ups in the system. Not surprisingly then, this work is also the first piece of scholarship to bring concepts from positive organizational scholarship to the teacher in her or his role of unit leader. Since there are over one million teachers in the United States alone, developing an understanding of the teacher in a broader organizational context offers the potential of surfacing important new insights.

Because the work of school improvement generally and teaching in particular has been cast in negative hues (Cassidy \& Bates, 2005 [105]; Luthans, 2002 [72]; Sarason, 1990 [58]), the application of positive organizational scholarship to teacher-leaders (and schooling more generally) has been quite limited. We undercut this pattern by emphasizing “the virtue of moral psychology” (Solomon, 1998, p. 515 [299]), “a positive moral perspective” (Walumbwa et al., 2008, p. 92 [276]), and “organizational virtuousness” (Caza et al., 2004, p. 74 [82]) in developing an understanding of teacher as leader of an organizational unit. We are "positively oriented, focused not on problems or deficits but on healthy development and function" (Rauner, 2000, p. 72 [282])—a "shift in emphasis in organizational development from 'fixing' organizational problems to identifying and growing organizational strengths” (Lawrence \& Maitlis, 2012 [269]). (See the edited volumes by Cameron, Dutton, \& Quinn, 2003 [300] and Snyder \& Lopez, 2009 [301] to explore this perspective.)

The article also provides an empirically and theoretically rich, mediated understanding of the pathways between the role of the teacher leader as provider of care and support and valued organizational outcomes. The model we develop establishes a productive framework for additional and more focused study of impacts of classroom units of schools. Because a culture of care and support has been associated with organizational performance, the idea of illuminating that pathway seems to be timely and important.

There is also a growing sense that teacher leadership in recent decades has lost its moorings in the relational aspects of classroom-based work. As we see in organizations in general, "the focus seems to be on individual traits and decision making rather than the more socially embedded” dimensions of the role (Glynn \& Jamerson, 2006, p. 157 [302]), “an overemphasis on the asocial dimensions” of the work (p. 158), and conceptions of job that underscore "following of routinized practices" (p. 164) that have the potential to push caring and supportive relationships to the sideline (Frost, 2003 [259]).

\section{References}

[1] Felner, R., Seitsinger, A., Brand, S., Burns, A. and Bolton, N. (2007) Creating Small Learning Communities: Lessons from the Project on High-Performing Learning Communities about "What Works" in Creating Productive, Developmentally Enhancing, Learning Contexts. Educational Psychologist, 42, 209-221. http://dx.doi.org/10.1080/00461520701621061

[2] Marks, H.M. (2000) Student Engagement in Instructional Activity: Patterns in the Elementary, Middle, and High School Years. American Educational Research Journal, 37, 153-184. http://dx.doi.org/10.3102/00028312037001153

[3] Sanders, M.G. and Harvey, A. (2002) Beyond the School Walls: A Case Study of Principal Leadership for SchoolCommunity Collaboration. Teachers College Record, 104, 1345-1368. http://dx.doi.org/10.1111/1467-9620.00206

[4] Tronto, J.C. (1993) Moral Boundaries: A Political Argument for an Ethic of Care. Routledge, New York.

[5] Burnier, D. (2003) Other Voices/Other Rooms: Towards a Care-Centered Public Administration. Administrative Theory \& Praxis, 25, 529-544.

[6] Fredricks, J.A., Blumenfeld, P.C. and Paris, A.H. (2004) School Engagement: Potential of the Concept, State of the Evidence. Review of Educational Research, 74, 59-109. http://dx.doi.org/10.3102/00346543074001059

[7] Newmann, F.M., Wehlage, G.G. and Lamburn, S.D. (1992) The Significance and Sources of Student Engagement. In: Newmann, F.M., Ed., Student Engagement and Achievement in American Secondary Schools, Teachers College Press, New York, 11-39.

[8] Wilson, B. and Corbett, H. (1999) No Excuses: The Eighth Grade Year in Six Philadelphia Middle Schools. Philadelphia Education Fund, Philadelphia.

[9] Kroth, M. and Keeler, C. (2009) Caring as a Managerial Strategy. Human Resource Development Review, 8, 506-531. http://dx.doi.org/10.1177/1534484309341558

[10] Autry, J.A. (1991) Love and Profit: The Art of Caring Leadership. Morrow, New York.

[11] Rodríguez, L.F. (2008) “Teachers Know You Can Do More”: Understanding How School Cultures of Success Affect Urban High School Students. Educational Policy, 22, 758-780. http://dx.doi.org/10.1177/0895904807307070 
[12] Walker, E.V.S. (1993) Interpersonal Caring in the "Good” Segregated Schooling of African-American Children: Evidence from the Case of Caswell County Training School. The Urban Review, 25, 63-77. http://dx.doi.org/10.1007/BF01108046

[13] Farrell, E. (1990) Hanging in and Dropping out: Voices of At-Risk High School Students. Teachers College Press, New York.

[14] Adams, C. (2010) Social Determinants of Student Trust in High Poverty Elementary Schools. In: Hoy, W.K. and DiPaola, M., Eds., Analyzing School Contexts: Influences of Principals and Teachers in the Service of Students, Information Age, Charlotte, 255-280.

[15] DePree, M. (1997) Leading without Power: Finding Hope in Serving Community. Jossey-Bass, San Francisco.

[16] DePree, M. (2003) Authentic Leadership: Rediscovering the Secrets to Creating Lasting Value. Jossey-Bass, San Francisco.

[17] DePree, M. (2004) Leadership is an Art. Doubleday, New York.

[18] Etzioni, A. (1993) The Spirit of Community: The Reinvention of American Society. Touchstone, New York.

[19] Raywid, M. (1995) Professional Community and Its Yield at Metro Academy. In: Louis, K.S. and Kruse, S., Eds., Professionalism and Community: Perspectives on Reforming Urban Schools, Corwin, Thousand Oaks, 43-75.

[20] Alexander, K. and Entwisle, D. (1996) Schools and Children at Risk. In: Booth, A. and Dunn, J., Eds., Family-School Links: How Do They Affect Educational Outcomes? Lawrence Erlbaum Associates, Mahwah, 67-88.

[21] Johnson Jr., J.F. and Asera, R. (1999) Hope for Urban Education: A Study of Nine High-Performing, High-Poverty, Urban Elementary Schools. U.S. Department of Education, Planning and Evaluation Services, Washington DC.

[22] Roth, J.L. and Brooks-Gunn, J. (2003) Youth Development Programs: Risk, Prevention and Policy. Journal of Adolescent Health, 32, 170-182. http://dx.doi.org/10.1016/S1054-139X(02)00421-4

[23] Antrop-González, R. and De Jesus, A. (2006) Toward a Theory of Critical Care in Urban Small School Reform: Examining Structures and Pedagogies of Caring in Two Latino Community-Based Schools. International Journal of Qualitative Studies in Education, 19, 409-433. http://dx.doi.org/10.1080/09518390600773148

[24] Shouse, R. (1996) Academic Press and Sense of Community: Conflict, Congruence, and Implications for Student Achievement. Social Psychology of Education, 1, 47-68. http://dx.doi.org/10.1007/BF02333405

[25] Joselowsky, F. (2007) Youth Engagement, High School Reform, and Improved Learning Outcomes: Building Systemic Approaches for Youth Engagement. NASSP Bulletin, 91, 253-276. http://dx.doi.org/10.1177/0192636507306133

[26] Alder, N. (2002) Interpretations of the Meaning of Care: Creating Caring Relationships in Urban Middle School Classrooms. Urban Education, 37, 241-266. http://dx.doi.org/10.1177/0042085902372005

[27] Ancess, J. (2003) Beating the Odds: High Schools as Communities of Commitment. Teachers College Press, New York.

[28] Antrop-González, R. (2006) Toward the "School as Sanctuary” Concept in Multicultural Urban Education: Implications for Small High School Reform. Curriculum Inquiry, 36, 273-301. http://dx.doi.org/10.1111/j.1467-873X.2006.00359.x

[29] Bru, E., Stephens, P. and Torsheim, T. (2002) Students' Perceptions of Class Management and Reports of Their Own Misbehavior. Journal of School Psychology, 40, 287-307. http://dx.doi.org/10.1016/S0022-4405(02)00104-8

[30] Ancess, J. (2000) The Reciprocal Influence of Teacher Learning, Teaching Practice, School Restructuring, and Student Learning Outcomes. The Teachers College Record, 102, 590-619. http://dx.doi.org/10.1111/0161-4681.00069

[31] Case, K.I. (1997) African American Other Mothering in the Urban Elementary School. The Urban Review, $29,25-39$. http://dx.doi.org/10.1023/A:1024645710209

[32] Battistich, V., Solomon, D., Kim, D., Watson, M. and Schaps, E. (1995) Schools as Communities, Poverty Levels of Student Populations, and Students' Attitudes, Motives, and Performance: A Multilevel Analysis. American Educational Research Journal, 32, 627-658. http://dx.doi.org/10.3102/00028312032003627

[33] Conchas, G. (2001) Structuring Failure and Success: Understanding the Variability in Latino School Engagement. Harvard Educational Review, 71, 475-505. http://dx.doi.org/10.17763/haer.71.3.280w814v1603473k

[34] Scheurich, J.J. (1998) Highly Successful and Loving, Public Elementary Schools Populated Mainly by Low-SES Children of Color. Urban Education, 33, 451-491. http://dx.doi.org/10.1177/0042085998033004001

[35] McLaughlin, M.W. and Talbert, J.E. (2001) Professional Communities and the Work of High School Teaching. University of Chicago Press, Chicago.

[36] Caldwell, C. and Dixon, R.D. (2009) Love, Forgiveness, and Trust: Critical Values of the Modern Leader. Journal of Business Ethics, 93, 91-101. http://dx.doi.org/10.1007/s10551-009-0184-z 
[37] Hattie, J. (2009) Visible Learning: A Synthesis of over 800 Meta-Analyses Relating to Achievement. Routledge, New York.

[38] Avolio, B.J., Gardner, W.L., Walumbwa, F.O., Luthans, F. and May, D.R. (2004) Unlocking the Mask: A Look at the Process by Which Authentic Leaders Impact Follower Attitudes and Behaviors. The Leadership Quarterly, 15, 801823. http://dx.doi.org/10.1016/j.leaqua.2004.09.003

[39] Cameron, K.S., Bright, D. and Caza, A. (2004) Exploring the Relationships between Organizational Virtuousness and Performance. American Behavioral Scientist, 47, 766-790. http://dx.doi.org/10.1177/0002764203260209

[40] Gardner, W.L., Avolio, B.J., Luthans, F., May, D.R. and Walumbwa, F. (2005) “Can You See the Real Me?” A Self-Based Model of Authentic Leader and Follower Development. The Leadership Quarterly, 16, 343-372. http://dx.doi.org/10.1016/j.leaqua.2005.03.003

[41] Reitzug, U.C. and Patterson, J. (1998) I'm Not Going to Lose You! Empowerment through Caring in an Urban Principal's Practice with Students. Urban Education, 33, 150-181. http://dx.doi.org/10.1177/0042085998033002002

[42] Luthans, F. and Avolio, B. (2003) Authentic Leadership Development. In: Cameron, K.S., Dutton, R.E. and Quinn, R.E., Eds., Positive Organizational Scholarship, Barrett-Koehler, San Francisco, 242-258.

[43] Patterson, N.C., Beltyukova, S.A., Berman, K. and Francis, A. (2007) The Making of Sophomores: Student, Parent, and Teacher Reactions in the Context of Systemic Urban High School Reform. Urban Education, 42, 124-144. http://dx.doi.org/10.1177/0042085906296538

[44] Croninger, R. and Lee, V. (2001) Social Capital and Dropping out of High School: Benefits to At-Risk Students of Teachers' Support and Guidance. Teachers College Record, 103, 548-581. http://dx.doi.org/10.1111/0161-4681.00127

[45] Galletta, A. and Ayala, J. (2008) Erasure and Survival: Creating a Future and Managing a Past in a Restructuring High School. Teachers College Record, 110, 1959-1985.

[46] McDougall, D., Saunders, W.M. and Goldenberg, C. (2007) Inside the Black Box of School Reform: Explaining the How and Why of Change at Getting Results Schools. International Journal of Disability, Development and Education, 54, 51-89. http://dx.doi.org/10.1080/10349120601149755

[47] Strahan, D. (2003) Promoting a Collaborative Professional Culture in Three Elementary Schools That Have Beaten the Odds. The Elementary School Journal, 104, 127-146. http://dx.doi.org/10.1086/499746

[48] Goddard, R.D. (2003) Relational Networks, Social Trust, and Norms: A Social Capital Perspective on Students' Chances of Academic Success. Educational Evaluation and Policy Analysis, 25, 59-74. http://dx.doi.org/10.3102/01623737025001059

[49] Noguera, P. (1996) Responding to the Crisis Confronting California's Black Male Youth: Providing Support without Furthering Marginalization. The Journal of Negro Education, 65, 219-236. http://dx.doi.org/10.2307/2967315

[50] Noddings, N. (1992) The Challenge to Care in Schools. Teachers College Press, New York.

[51] Steele, C.M. (1992) Race and the Schooling of Black Americans. Atlantic Monthly, 269, 68-78.

[52] Cooper, J.E., Ponder, G., Merritt, S. and Matthews, C. (2005) High-Performing High Schools: Patterns of Success. NASSP Bulletin, 89, 2-23. http://dx.doi.org/10.1177/019263650508964502

[53] Darling-Hammond, L., Ancess, J. and Ort, S. (2002) Reinventing High School: Outcomes of the Coalition Campus Schools Project. American Educational Research Journal, 39, 639-673. http://dx.doi.org/10.3102/00028312039003639

[54] Birch, S.H. and Ladd, G.W. (1997) The Teacher-Child Relationship and Children’s Early School Adjustment. Journal of School Psychology, 35, 61-79. http://dx.doi.org/10.1016/S0022-4405(96)00029-5

[55] Opdenakker, M., Maulana, R. and Brock, P. (2012) Teacher-Student Interpersonal Relationships and Academic Motivation within One School Year: Developmental Changes and Linkage. School Effectiveness and School Improvement, 21, 95-199. http://dx.doi.org/10.1080/09243453.2011.619198

[56] Newmann, F.M. (1981) Reducing Student Alienation in High Schools: Implications of Theory. Harvard Educational Review, 51, 546-564. http://dx.doi.org/10.17763/haer.51.4.xj67887u8715t66t

[57] Roney, K., Coleman, H. and Schlichting, K.A. (2007) Linking the Organizational Health of Middle Grades Schools to Student Achievement. NASSP Bulletin, 91, 289-321. http://dx.doi.org/10.1177/0192636507310161

[58] Sarason, S.B. (1990) The Predictable Failure of Educational Reform: Can We Change Course before It's Too Late? The Jossey-Bass Education Series and the Jossey-Bass Social and Behavioral Science Series. ERIC. http://eric.ed.gov/?id=ED354587

[59] Csikszentmihalyi, M. and Larson, R. (1984) Being Adolescent: Conflict and Growth in the Teenage Years. Basic Books, New York.

[60] Bulkley, K.E. and Hicks, J. (2005) Managing Community: Professional Community in Charter Schools Operated by Educational Management Organizations. Educational Administration Quarterly, 41, 306-348. 
http://dx.doi.org/10.1177/0013161X04269594

[61] Day, C. (2005) Sustaining Success in Challenging Contexts: Leadership in English Schools. Journal of Educational Administration, 43, 573-583. http://dx.doi.org/10.1108/09578230510625674

[62] Quint, J. (2006) Meeting Five Critical Challenges of High School Reform: Lessons from Research on Three Reform Models. Manpower Demonstration Research Corporation, New York.

[63] Becker, B.E. and Luthar, S.S. (2002) Social-Emotional Factors Affecting Achievement Outcomes among Disadvantaged Students: Closing the Achievement Gap. Educational Psychologist, 37, 197-214. http://dx.doi.org/10.1207/S15326985EP3704 1

[64] Gardner, W.L. and Schermerhorn Jr., J.R. (2004) Unleashing Individual Potential: Performance Gains through Positive Organizational Behavior and Authentic Leadership. Organizational Dynamics, 33, 270-281. http://dx.doi.org/10.1016/j.orgdyn.2004.06.004

[65] Webb, J., Wilson, B., Corbett, D. and Mordecai, R. (1993) Understanding Caring in Context: Negotiating Borders and Barriers. The Urban Review, 25, 25-45. http://dx.doi.org/10.1007/BF01108044

[66] Kelsey, M.T. (1981) Caring: How Can We Love One Another? Paulist Press, New York.

[67] Burton, B.K. and Dunn, C.P. (2005) The Caring Approach and Social Issues in Management Education. Journal of Management Education, 29, 453-474. http://dx.doi.org/10.1177/1052562904267624

[68] Clement, G. (1996) Care, Autonomy, and Justice: Feminism and the Ethic of Care. http://philpapers.org/rec/clecaa

[69] Avolio, B.J. and Gardner, W.L. (2005) Authentic Leadership Development: Getting to the Root of Positive Forms of Leadership. The Leadership Quarterly, 16, 315-338. http://dx.doi.org/10.1016/j.leaqua.2005.03.001

[70] Battistich, V. and Hom, A. (1997) The Relationship between Students' Sense of Their School as a Community and Their Involvement in Problem Behaviors. American Journal of Public Health, 87, 1997-2001. http://dx.doi.org/10.2105/AJPH.87.12.1997

[71] Fredrickson, B.L. (2001) The Role of Positive Emotions in Positive Psychology: The Broaden-and-Build Theory of Positive Emotions. American Psychologist, 56, 218. http://dx.doi.org/10.1037/0003-066X.56.3.218

[72] Luthans, F. and Church, A. (2002) Positive Organizational Behavior: Developing and Managing Psychological Strengths. Academy of Management, 16, 57-75. http://dx.doi.org/10.5465/ame.2002.6640181

[73] Adams, C. and Forsyth, P. (2009) Conceptualizing and Validating a Measure of Student Trust. In: Hoy, W.K. and DiPoala, M., Eds., Studies in School Improvement, Information Age, Charlotte, 263-277.

[74] Vanier, J. (1998) Becoming Human. Paulist Press, Mahwah.

[75] Leithwood, K., Jantzi, D. and Steinbach, R. (1999) Changing Leadership for Changing Times. Open University Press, Philadelphia.

[76] Gonzalez, R. and Padilla, A.M. (1997) The Academic Resilience of Mexican American High School Students. Hispanic Journal of Behavioral Sciences, 19, 301-317. http://dx.doi.org/10.1177/07399863970193004

[77] Scanlan, M. and Lopez, F. (2012) Vamos! How School Leaders Promote Equity and Excellence for Bilingual Students. Educational Administration Quarterly, 48, 583-625. http://dx.doi.org/10.1177/0013161X11436270

[78] Ehrhart, M.G. (2004) Leadership and Procedural Justice Climate as Antecedents of Unit-Level Organizational Citizenship Behavior. Personnel Psychology, 57, 61-94. http://dx.doi.org/10.1111/j.1744-6570.2004.tb02484.x

[79] Dirks, K.T. and Ferrin, D.L. (2002) Trust in Leadership: Meta-Analytic Findings and Implications for Research and Practice. Journal of Applied Psychology, 87, 611. http://dx.doi.org/10.1037/0021-9010.87.4.611

[80] Foster, R. and St. Hilaire, B. (2003) Leadership for School Improvement: Principals' and Teachers Perspectives. International Electronic Journal for Leadership in Learning, 7, 1-18.

[81] Sather, S.E. (1999) Leading, Lauding, and Learning: Leadership in Secondary Schools Serving Diverse Populations. Journal of Negro Education, 511-528. http://dx.doi.org/10.2307/2668151

[82] Caza, A., Barker, B.A. and Cameron, K.S. (2004) Ethics and Ethos: The Buffering and Amplifying Effects of Ethical Behavior and Virtuousness. Journal of Business Ethics, 52, 169-178. http://dx.doi.org/10.1023/B:BUSI.0000035909.05560.0e

[83] Bloomberg, L., Ganey, A., Alba, V., Quintero, G. and Alvarez-Alcantara, L. (2003) Chicano-Latino Youth Leadership Institute: An Asset-Based Program for Youth. American Journal of Health Behavior, 27, 45-54. http://dx.doi.org/10.5993/AJHB.27.1.s1.5

[84] Demaray, M.K. and Malecki, C.K. (2002) The Relationship between Perceived Social Support and Maladjustment for Students at Risk. Psychology in the Schools, 39, 305-316. http://dx.doi.org/10.1002/pits.10018

[85] Louis, K.S. and Marks, H.M. (1998) Does Professional Community Affect the Classroom? Teachers’ Work and Stu- 
dent Work in Restructuring Schools. American Journal of Education, 106, 532-575. http://dx.doi.org/10.1086/444197

[86] Greenleaf, R.K. (1977) Servant Leadership: A Journey into the Nature of Legitimate Power and Greatness. Paulist Press, New York.

[87] Jackson, Y. and Warren, J.S. (2000) Appraisal, Social Support, and Life Events: Predicting Outcome Behavior in School-Age Children. Child Development, 71, 1441-1457. http://dx.doi.org/10.1111/1467-8624.00238

[88] Maguin, E. and Loeber, R. (1996) Academic Performance and Delinquency. In: Tonry, M., Ed., Crime and Justice, Vol. 20, University of Chicago Press, Chicago, 145-264. http://dx.doi.org/10.1086/449243

[89] Balfanz, R., Herzog, L. and MacIver, D. (2007) Preventing Student Disengagement and Keeping Students on the Graduation Path in Urban Middle-Grades Schools: Early Identification and Effective Interventions. Educational Psychologist, 42, 223-235. http://dx.doi.org/10.1080/00461520701621079

[90] Crosnoe, R. (2011) Fitting in, Standing out: Navigating the Social Challenges of High School to Get an Education. Cambridge University Press, Cambridge. http://dx.doi.org/10.1017/CBO9780511793264

[91] Newmann, F.M. (1992) Conclusion. In: Newmann, F.M., Ed., Student Engagement and Achievement in American Secondary Schools, Teachers College Record, New York, 182-217. http://dx.doi.org/10.1007/978-1-349-12661-3_9

[92] Roth, J.L., Brooks-Gunn, J., Murray, L. and Foster, W. (1998) Promoting Healthy Adolescents: Synthesis of Youth Development Program Evaluations. Journal of Research on Adolescence, 8, 423-459. http://dx.doi.org/10.1207/s15327795jra0804_2

[93] Hoy, W., Hannum, J. and Tschannen-Moran, M. (1998) Organizational Climate and Student Achievement: A Parsimonious and Longitudinal View. Journal of School Leadership, 8, 336-359.

[94] Allensworth, E.M. and Easton, J.Q. (2005) The On-Track Indicator as a Predictor of High School Graduation. Consortium on Chicago School Research at the University of Chicago, Chicago.

[95] Gray, J., Hopkins, D., Reynolds, D., Wilcox, B., Farrell, S. and Jesson, D. (1999) Improving Schools: Performance and Potential. Open University Press, Philadelphia.

[96] Woloszyk, C. (1996) Models for At-Risk Youth. Final Report. Upjohn Institute for Employment Research, Kalamazoo.

[97] Benner, P. (1994) Understanding Caring in Contemporary America. In: Phillips, S. and Benner, P., Eds., The Crisis of Care: Affirming and Restoring Caring Practices in the Helping Professions, Georgetown University Press, Washington DC, 42-62.

[98] Rumberger, R. (2011) Dropping out: Why Students Drop out of High School and What Can Be Done about It. Harvard University Press, Cambridge. http://dx.doi.org/10.4159/harvard.9780674063167

[99] O’Connor, M.J. (1997) Managing by Values. Berrett-Koehler Publishers.

[100] Willms, J.D. (2000) A Sense of Belonging and Participation: Results from PISA 2000. http://www.oecd.org/edu/school/programmeforinternationalstudentassessmentpisa/33689437.pdf

[101] Bosworth, K. and Ferreira, M. (2000) Context as a Critical Factor in Young Adolescents' Concepts of Caring. Journal of Research in Childhood Education, 15, 117-128. http://dx.doi.org/10.1080/02568540009594780

[102] Kershner, R. (1996) The Meaning of “Working Hard” in School. In: Rudduck, J., Chaplain, R.P. and Wallace, G., Eds., School Improvement: What Can Pupils Tell Us? Routledge, London, 66-81.

[103] Roeser, R.W., Eccles, J.S. and Sameroff, A.J. (2000) School as a Context of Early Adolescents’ Academic and SocialEmotional Development: A Summary of Research Findings. The Elementary School Journal, 100, 443-471. http://dx.doi.org/10.1086/499650

[104] Nichols, S.L. (2006) Teachers’ and Students’ Beliefs about Student Belonging in One Middle School. The Elementary School Journal, 106, 255-271. http://dx.doi.org/10.1086/501486

[105] Cassidy, W. and Bates, A. (2005) "Drop-Outs" and "Push-Outs": Finding Hope at a School That Actualizes the Ethic of Care. American Journal of Education, 112, 66-102. http://dx.doi.org/10.1086/444524

[106] Feldman, A. and Matjasko, J. (2005) The Role of School-Based Extracurricular Activities in Adolescent Development: A Comprehensive Review and Future Directions. Review of Educational Research, 75, 159-210. http://dx.doi.org/10.3102/00346543075002159

[107] Gibson, M.A., Bejinez, L.F., Hidalgo, N. and Rolón, C. (2004) Belonging and School Participation: Lessons from a Migrant Student Club. In: Gibson, M.A., Gándara, P. and Koyama, J.P., Eds., School Connections: U. S. Mexican Youth, Peers, and School Achievement, Teachers College Press, New York, 129-149.

[108] Marsh, H.W. and Kleitman, S. (2002) Extracurricular School Activities: The Good, the Bad, and the Nonlinear. Harvard Educational Review, 72, 464-515. http://dx.doi.org/10.17763/haer.72.4.051388703v7v7736

[109] Kennedy, B.L. (2011) The Importance of Student and Teacher Interactions for Disaffected Middle School Students: A Grounded Theory Study of Community Day Schools. Urban Education, 46, 4-33. 
http://dx.doi.org/10.1177/0042085910377305

[110] Smerdon, B.A. (2002) Students’ Perceptions of Membership in Their High Schools. Sociology of Education, 75, 287305. http://dx.doi.org/10.2307/3090280

[111] Johnson, L.S. (2009) School Contexts and Student Belonging: A Mixed Methods Study of an Innovative High School. School Community Journal, 19, 99-118.

[112] Goodenow, C. and Grady, K.E. (1993) The Relationship of School Belonging and Friends' Values to Academic Motivation among Urban Adolescent Students. The Journal of Experimental Education, 62, 60-71. http://dx.doi.org/10.1080/00220973.1993.9943831

[113] Pavri, S. and Monda-Amaya, L. (2001) Social Support in Inclusive Schools: Student and Teacher Perspectives. Exceptional Children, 67, 391-411.

[114] McMahon, S.D. and Wernsman, J. (2009) The Relation of Classroom Environment and School Belonging to Academic Self-Efficacy among Urban Fourth- and Fifth-Grade Students. The Elementary School Journal, 109, 267-281. http://dx.doi.org/10.1086/592307

[115] Kroeger, S. (2004) Student Voice and Critical Reflection. Teaching Exceptional Children, 36, 50-57. http://dx.doi.org/10.1177/004005990403600307

[116] Connell, J.P. and Wellborn, J.G. (1991) Competence, Autonomy, and Relatedness: A Motivational Analysis of SelfSystem Processes. In Gunnar, M.R. and Sroufe, L.A., Eds., Minnesota Symposia on Child Psychology, Vol. 23, Lawrence Erlbaum, Hillsdale, 43-77.

[117] Cabello, B. and Terrell, R. (1994) Making Students Feel Like Family: How Teachers Create Warm and Caring Classroom Climates. Journal of Classroom Interaction, 29, 17-23.

[118] Nieto, S. (1994) Lessons from Students on Creating a Chance to Dream. Harvard Educational Review, 64, 392-427. http://dx.doi.org/10.17763/haer.64.4.4846361m306pl670

[119] Oldfather, P., Thomas, S., Eckert, L., Garcia, F., Grannis, N., Kilgore, J. and Tjioe, M. (1999) The Nature and Outcomes of Students' Longitudinal Participatory Research on Literacy Motivations and Schooling. Research in the Teaching of English, 34, 281-320.

[120] Burke, C. and Grosvenor, I. (2003) The School I'd Like: Children and Young People's Reflections on an Education for the 21st Century. Routledge, London.

[121] Cotterell, J.L. (1992) The Relation of Attachments and Supports to Adolescent Well-Being and School Adjustment. Journal of Adolescent Research, 7, 28-42. http://dx.doi.org/10.1177/074355489271003

[122] Goodenow, C. (1993) Classroom Belonging among Early Adolescent Students Relationships to Motivation and Achievement. The Journal of Early Adolescence, 13, 21-43. http://dx.doi.org/10.1177/0272431693013001002

[123] Judson, Q., Cohen-Dan, J., Leonard, T., Stinson, S. and Colston, T. (2001) Speaking out Loud: Girls Seeking Selfhood. In: Our Own Words: Students' Perspectives on School, Rowman \& Littlefield, New York, 39-56.

[124] Eckert, P. (1989) Jocks and Burnouts: Social Categories and Identity in the High School. Teachers College Press, New York.

[125] Alexander, K., Entwisle, D. and Horsey, C. (1997) From First Grade Forward: Early Foundations of High School Dropout. Sociology of Education, 70, 87-107. http://dx.doi.org/10.2307/2673158

[126] van Dierendonck, D. and Patterson, K. (2014) Compassionate Love as a Cornerstone of Servant Leadership: An Integration of Previous Theorizing and Research. Journal of Business Ethics, 1-13.

[127] Voelkl, K.E. (1997) Identification with School. American Journal of Education, 105, 294-318. http://dx.doi.org/10.1086/444158

[128] Fine, M. (1986) Why Urban Adolescents Drop into and out of Public High School. The Teachers College Record, 87, 393-409.

[129] Kosciw, J.G., Greytak, E.A., Bartkiewicz, M.J., Boesen, M.J. and Palmer, N.A. (2012) The 2011 National School Climate Survey: The Experiences of Lesbian, Gay, Bisexual and Transgender Youth in Our Nation's Schools. Gay, Lesbian and Straight Education Network (GLSEN), New York.

[130] Lee, P.W. (1999) In Their Own Voices: An Ethnographic Study of Low-Achieving Students within the Context of School Reform. Urban Education, 34, 214-244. http://dx.doi.org/10.1177/0042085999342005

[131] Anderman, L.H. (2003) Academic and Social Perceptions as Predictors of Change in Middle School Students' Sense of School Belonging. The Journal of Experimental Education, 72, 5-22. http://dx.doi.org/10.1080/00220970309600877

[132] Crosnoe, R., Johnson, M.K. and Elder, G.H. (2004) Intergenerational Bonding in School: The Behavioral and Contextual Correlates of Student-Teacher Relationships. Sociology of Education, 77, 60-81. http://dx.doi.org/10.1177/003804070407700103 
[133] Gittell, J.H. (2000) Organizing Work to Support Relational Co-Ordination. International Journal of Human Resource Management, 11, 517-539. http://dx.doi.org/10.1080/095851900339747

[134] Dutton, J.E. and Heaphy, E.D. (2003) The Power of High-Quality Connections. In: Cameron, K. and Dutton, J., Eds., Positive Organizational Scholarship: Foundations of a New Discipline, Berrett-Koehler Publishers, 262-278.

[135] Miller, T.L., Grimes, M.G., McMullen, J.S. and Vogus, T.J. (2012) Venturing for Others with Heart and Head: How Compassion Encourages Social Entrepreneurship. Academy of Management Review, 37, 616-640. http://dx.doi.org/10.5465/amr.2010.0456

[136] McNeal, R.B. (1999) Participation in High School Extracurricular Activities: Investigating School Effects. Social Science Quarterly, 80, 291-309.

[137] Gamoran, A. (1996) Effects of Schooling on Children and Families. In: Booth, A. and Dunn, J., Eds., Family-School Links: How Do They Affect Educational Outcomes? Lawrence Erlbaum Associates, Mahwah, 107-114.

[138] Baker, J.A., Terry, T., Bridger, R. and Winsor, A. (1997) Schools as Caring Communities: A Relational Approach to School Reform. The School Psychology Review, 26, 586-602.

[139] Marsh, H.W. and Kleitman, S. (1992) Extracurricular Activities: Beneficial Extension of the Traditional Curriculum or Subversion of Academic Goals? Journal of Educational Psychology, 84, 553-562. http://dx.doi.org/10.1037/0022-0663.84.4.553

[140] Battistich, V., Solomon, D., Watson, M. and Schaps, E. (1997) Caring School Communities. Educational Psychologist, 32, 137-151. http://dx.doi.org/10.1207/s15326985ep3203_1

[141] Hallinan, M.T. and Kubitschek, W.N. (1999) Curriculum Differentiation and High School Achievement. Social Psychology of Education, 3, 41-62. http://dx.doi.org/10.1023/A:1009603706414

[142] Freiberg, H.J., Huzinec, C.A. and Templeton, S.M. (2009) Classroom Management-A Pathway to Student Achievement: A Study of Fourteen Inner-City Elementary Schools. The Elementary School Journal, 110, 63-80. http://dx.doi.org/10.1086/598843

[143] Kuperminc, G.P., Leadbeater, B.J., Emmons, C. and Blatt, S.J. (1997) Perceived School Climate and Difficulties in the Social Adjustment of Middle School Students. Applied Developmental Science, 1, 76-88. http://dx.doi.org/10.1207/s1532480xads0102_2

[144] Murdock, T.B. and Miller, A. (2003) Teachers as Sources of Middle School Students’ Motivational Identity: VariableCentered and Person-Centered Analytic Approaches. The Elementary School Journal, 103, 383-399. http://dx.doi.org/10.1086/499732

[145] Murdock, T.B., Anderman, L.H. and Hodge, S.A. (2000) Middle-Grade Predictors of Students' Motivation and Behavior in High School. Journal of Adolescent Research, 15, 327-351. http://dx.doi.org/10.1177/0743558400153002

[146] Oelsner, J., Lippold, M.A. and Greenberg, M.T. (2011) Factors Influencing the Development of School Bonding among Middle School Students. The Journal of Early Adolescence, 31, 463-487. http://dx.doi.org/10.1177/0272431610366244

[147] Wilson, T., Karimpour, R. and Rodkin, P.C. (2011) African American and European American Students' Peer Groups during Early Adolescence: Structure, Status, and Academic Achievement. The Journal of Early Adolescence, 31, 7498. http://dx.doi.org/10.1177/0272431610387143

[148] Booker, K.C. (2006) School Belonging and the African American Adolescent: What Do We Know and Where Should We Go? The High School Journal, 89, 1-7. http://dx.doi.org/10.1353/hsj.2006.0005

[149] Wilson, S.M. and Ferch, S.R. (2005) Enhancing Resilience in the Workplace through the Practice of Caring Relationships. Organization Development Journal, 23, 45.

[150] Phelan, P., Davidson, A.L. and Cao, H.T. (1992) Speaking up: Students’ Perspectives on School. The Phi Delta Kappan, 73, 695-704.

[151] Quiroz, P.A. (2001) The Silencing of Latino Student "Voice”: Puerto Rican and Mexican Narratives in Eighth Grade and High School. Anthropology \& Education Quarterly, 32, 326-349. http://dx.doi.org/10.1525/aeq.2001.32.3.326

[152] Lehr, C.A., Sinclair, M.F. and Christenson, S.L. (2004) Addressing Student Engagement and Truancy Prevention during the Elementary School Years: A Replication Study of the Check \& Connect Model. Journal of Education for Students Placed at Risk, 9, 279-301. http://dx.doi.org/10.1207/s15327671espr0903_4

[153] Goddard, H. and Goff, B. (1999) Terminal Core Values Associated with Adolescent Problem Behaviors. Adolescence, 34, 47-54.

[154] Flutter, J. and Rudduck, J. (2004) Consulting Pupils: What's in It for Schools? Routledge, London.

[155] Davis, H.A. (2003) Conceptualizing the Role and Influence of Student-Teacher Relationships on Children's Social and Cognitive Development. Educational Psychologist, 38, 207-234. http://dx.doi.org/10.1207/S15326985EP3804_2 
[156] Wigfield, A., Eccles, J.S. and Pintrich, P.R. (1998) Relations of Young Children’s Ability-Related Beliefs to Their Subjective Task Values, Performance, and Effort. Paper Presented at the International Conference of Applied Psychology, San Francisco.

[157] McNeely, C.A., Nonnemaker, J.M. and Blum, R.W. (2002) Promoting School Connectedness: Evidence from the National Longitudinal Study of Adolescent Health. Journal of School Health, 72, 138-146. http://dx.doi.org/10.1111/j.1746-1561.2002.tb06533.x

[158] Harter, S. (1990) Issues in the Assessment of the Self-Concept of Children and Adolescents. In: La Greca, A.M., Ed., Through the Eyes of the Child: Obtaining Self-Reports from Children and Adolescents, Allyn \& Bacon, Needham Heights, 292-325.

[159] DuBois, D.L., Felner, R.D., Brand, S. and Phillips, R.S. (1996) Early Adolescent Self-Esteem: A DevelopmentalEcological Framework and Assessment Strategy. Journal of Research on Adolescence, 6, 543-579.

[160] Saunders, J., Davis, L., Williams, T. and Williams, J.H. (2004) Gender Differences in Self-Perceptions and Academic Outcomes: A Study of African American High School Students. Journal of Youth and Adolescence, 33, 81-90. http://dx.doi.org/10.1023/A:1027390531768

[161] Harter, S., Waters, P.L. and Whitesell, N.R. (1997) Lack of Voice as a Manifestation of False Self-Behavior among Adolescents: The School Setting as a Stage upon Which the Drama of Authenticity Is Enacted. Educational Psychologist, 32, 153-173. http://dx.doi.org/10.1207/s15326985ep3203_2

[162] Thompson, G.L. (2004) Through Ebony Eyes: What Teachers Need to Know but Are Afraid to Ask about AfricanAmerican Students. Jossey-Bass, San Francisco.

[163] Davis, H.A. (2001) The Quality and Impact of Relationships between Elementary School Students and Teachers. Contemporary Educational Psychology, 26, 431-453. http://dx.doi.org/10.1006/ceps.2000.1068

[164] Walumbwa, F.O., Mayer, D.M., Wang, P., Wang, H., Workman, K. and Christensen, A.L. (2011) Linking Ethical Leadership to Employee Performance: The Roles of Leader-Member Exchange, Self-Efficacy, and Organizational Identification. Organizational Behavior and Human Decision Processes, 115, 204-213. http://dx.doi.org/10.1016/j.obhdp.2010.11.002

[165] Chaplain, R. (1996) Pupils under Pressure: Coping with Stress at School. In: Rudduck, J., Chaplain, R.P. and Wallace, G., Eds., School Improvement: What Can Pupils Tell Us? Routledge, London, 116-127.

[166] Shade, B.J., Kelly, C.A. and Oberg, M. (1997) Creating Culturally Responsive Classrooms. American Psychological Association, Washington DC. http://dx.doi.org/10.1037/10268-000

[167] Eccles-Parsons, J., Adler, T.F., Futterman, R., Goff, S.B., Kaczala, C.M., Meece, J.L. and Midgley, C. (1983) Expectancies, Values, and Academic Behaviors. In: Spence, J.T., Ed., Achievement and Achievement Motivation, W. H. Freeman, San Francisco, 75-149.

[168] Bandura, A. (1993) Perceived Self-Efficacy in Cognitive Development and Functioning. Educational Psychologist, 28, 117-148. http://dx.doi.org/10.1207/s15326985ep2802_3

[169] Newmann, F.M., Rutter, R.A. and Smith, M.S. (1989) Organizational Factors That Affect School Sense of Efficacy, Community, and Expectations. Sociology of Education, 62, 221-238. http://dx.doi.org/10.2307/2112828

[170] Pintrich, P.R. (2003) A Motivational Science Perspective on the Role of Student Motivation in Learning and Teaching Contexts. Journal of Educational Psychology, 95, 667-686. http://dx.doi.org/10.1037/0022-0663.95.4.667

[171] Maehr, M.L. and Midgley, C. (1996) Transforming School Cultures. Westview Press, Boulder.

[172] Masten, A.S., Best, K.M. and Garmezy, N. (1990) Resilience and Development: Contributions from the Study of Children Who Overcome Adversity. Development and Psychopathology, 2, 425-444. http://dx.doi.org/10.1017/S0954579400005812

[173] Rudduck, J. (2007) Student Voice, Student Engagement, and School Reform. In: Thiessen, D. and Cook-Sather, A., Eds., International Handbook of Student Experience in Elementary and Secondary School, Springer, Netherlands, 587610. http://dx.doi.org/10.1007/1-4020-3367-2 23

[174] Skaalvik, E.M. and Hagtvet, K.A. (1990) Academic Achievement and Self-Concept: An Analysis of Causal Predominance in a Developmental Perspective. Journal of Personality and Social Psychology, 58, 292-307. http://dx.doi.org/10.1037/0022-3514.58.2.292

[175] Stajkovic, A.D. and Luthans, F. (1998) Self-Efficacy and Work-Related Performance. Psychological Bulletin, 124, 240-261. http://dx.doi.org/10.1037/0033-2909.124.2.240

[176] Hoge, D.R., Smit, E.K. and Hanson, S.L. (1990) School Experiences Predicting Changes in Self-Esteem of Sixth- and Seventh-Grade Students. Journal of Educational Psychology, 82, 117-127. http://dx.doi.org/10.1037/0022-0663.82.1.117

[177] Harter, S. (1996) Teacher and Classmate Influences on Scholastic Motivation, Self-Esteem, and Level of Voice of 
Students. In: Juvonen, J. and Wentzel, K.R., Eds., Teacher and Classmate Influences on Scholastic Motivation, Self Esteem, and Level of Voice in Adolescents, Cambridge University Press, New York, 11-44.

[178] Pianta, R.C. (1999) Enhancing Relationships between Children and Teachers. American Psychological Association, Washington DC. http://dx.doi.org/10.1037/10314-000

[179] Wentzel, K.R. (2002) Are Effective Teachers Like Good Parents? Teaching Styles and Student Adjustment in Early Adolescence. Child Development, 73, 287-301. http://dx.doi.org/10.1111/1467-8624.00406

[180] Moos, R. and Trickett, E. (1987) Classroom Environment Scale Manual. 2nd Edition, Consulting Psychologists Press, Palo Alto.

[181] Ryan, R.M., Stiller, J.D. and Lynch, J.H. (1994) Representations of Relationships to Teachers, Parents, and Friends as Predictors of Academic Motivation and Self-Esteem. The Journal of Early Adolescence, 14, 226-249. http://dx.doi.org/10.1177/027243169401400207

[182] Davidson, H.H. and Lang, G. (1960) Children's Perceptions of Their Teachers' Feelings toward Them Related to SelfPerception, School Achievement and Behavior. The Journal of Experimental Education, 29, 107-118. http://dx.doi.org/10.1080/00220973.1960.11010675

[183] Gittell, J.H. (2003) A Theory of Relational Coordination. In: Cameron, K. and Dutton, J., Eds., Positive Organizational Scholarship: Foundations of a New Discipline, Berrett-Koehler Publishers, 279-295.

[184] Weinstein, R.S. (1983) Student Perceptions of Schooling. The Elementary School Journal, 83, 287-312. http://dx.doi.org/10.1086/461319

[185] Guest, A. and Schneider, B. (2003) Adolescents’ Extracurricular Participation in Context: The Mediating Effects of Schools. Sociology of Education, 76, 89-109. http://dx.doi.org/10.2307/3090271

[186] Pounder, D.G. (1999) Teacher Teams: Exploring Job Characteristics and Work-Related Outcomes of Work Group Enhancement. Educational Administration Quarterly, 35, 317-348. http://dx.doi.org/10.1177/0013161X99353002

[187] Rothman, H.R. and Cosden, M. (1995) The Relationship between Self-Perception of a Learning Disability and Achievement, Self-Concept and Social Support. Learning Disability Quarterly, 18, 203-212. http://dx.doi.org/10.2307/1511043

[188] Finn, J.D. and Rock, D. (1997) Academic Success among Students at Risk for School Failure. Journal of Applied Psychology, 82, 221-234. http://dx.doi.org/10.1037/0021-9010.82.2.221

[189] Mulford, B. and Silins, H. (2003) Leadership for Organisational Learning and Improved Student Outcomes—What Do We Know. Cambridge Journal of Education, 33, 175-195. http://dx.doi.org/10.1080/03057640302041

[190] Feldlaufer, H., Midgley, C. and Eccles, J.S. (1988) Student, Teacher, and Observer Perceptions of the Classroom Environment before and after the Transition to Junior High School. The Journal of Early Adolescence, 8, 133-156. http://dx.doi.org/10.1177/0272431688082003

[191] Dillon, D.R. (1989) Showing Them That I Want Them to Learn and That I Care about Who They Are: A Microethnography of the Social Organization of a Secondary Low-Track English-Reading Classroom. American Educational Research Journal, 26, 227-259. http://dx.doi.org/10.3102/00028312026002227

[192] Caprara, G.V., Alessandri, G. and Eisenberg, N. (2012) Prosociality: The Contribution of Traits, Values, and SelfEfficacy Beliefs. Journal of Personality and Social Psychology, 102, 1289. http://dx.doi.org/10.1037/a0025626

[193] Garmezy, N. (1991) Resilience and Vulnerability to Adverse Developmental Outcomes Associated with Poverty. American Behavioral Scientist, 34, 416-430. http://dx.doi.org/10.1177/0002764291034004003

[194] Rudduck, J. (1996) Getting Serious: The Demands of Coursework, Revision, and Examinations. In: Rudduck, J., Chaplain, R.P. and Wallace, G., Eds., School Improvement: What Can Pupils Tell Us? Routledge, London, 129-141.

[195] Bagozzi, R.P. (2003) Positive and Negative Emotions in Organizations. In: Cameron, K.S., Dutton, R.E. and Quinn, R.E., Eds., Positive Organizational Scholarship, Barrett-Koehler, San Francisco, 173-196.

[196] Chaplain, R. (1996) Making a Strategic Withdrawal: Disengagement and Self-Worth Protection in Male Pupils. In: Rudduck, J., Chaplain, R.P. and Wallace, G., Eds., School Improvement: What Can Pupils Tell Us? Routledge, London, 97-111.

[197] Boekaerts, M. (1993) Being Concerned with Well-Being and with Learning. Educational Psychologist, 28, $149-167$. http://dx.doi.org/10.1207/s15326985ep2802_4

[198] Fine, M., Torre, M.E., Burns, A. and Payne, Y.A. (2007) Youth Research/Participatory Methods for Reform. In: Thiessen, D. and Cook-Sather, A., Eds., International Handbook of Student Experience in Elementary and Secondary School, Springer, Netherlands, 805-828. http://dx.doi.org/10.1007/1-4020-3367-2_32

[199] Ma, X. (2003) Sense of Belonging to School: Can Schools Make a Difference? The Journal of Educational Research, 96, 340-349. http://dx.doi.org/10.1080/00220670309596617 
[200] McNeal, R.B. (1998) High School Extracurricular Activities: Closed Structures and Stratifying Patterns of Participation. The Journal of Educational Research, 91, 183-191. http://dx.doi.org/10.1080/00220679809597539

[201] Rudduck, J., Chaplain, R. and Wallace, G. (1996) Reviewing the Conditions of Learning in School. In: Rudduck, J., Chaplain, R. and Wallace, G., Eds., School Improvement: What Students Can Tell Us? David Fulton Publishers, London, 170-176.

[202] Furrer, C. and Skinner, E. (2003) Sense of Relatedness as a Factor in Children’s Academic Engagement and Performance. Journal of Educational Psychology, 95, 148-162. http://dx.doi.org/10.1037/0022-0663.95.1.148

[203] Appleton, J.J., Christenson, S.L. and Furlong, M.J. (2008) Student Engagement with School: Critical Conceptual and Methodological Issues of the Construct. Psychology in the Schools, 45, 369-386. http://dx.doi.org/10.1002/pits.20303

[204] Rudduck, J. and Flutter, J. (2004) How to Improve Your School. Continuum International Publishing Group, London.

[205] Silverstein, B. and Krate, R. (1975) Children of the Dark Ghetto: A Developmental Psychology. Praeger, Oxford.

[206] Owens, B. and Hekman, D. (2012) Modeling How to Grow: An Inductive Examination of Humble Leader Behaviors, Contingencies, and Outcomes. Academy of Management Journal, 55, 787-818. http://dx.doi.org/10.5465/amj.2010.0441

[207] Maehr, M.L. and Fyans Jr., L.J. (1989) School Culture, Motivation, and Achievement. In: Maehr, M.L. and Ames, C., Eds., Advances in Motivation and Achievement: Motivation Enhancing Environments, Vol. 6, JAI, Greenwich, 215247.

[208] Kropiewnicki, M.I. and Shapiro, J.P. (2001) Female Leadership and the Ethic of Care: Three Case Studies. Paper Presented at the Annual Meeting of the American Educational Research Association, Seattle.

[209] Graham, S., Taylor, A.Z. and Hudley, C. (1998) Exploring Achievement Values among Ethnic Minority Early Adolescents. Journal of Educational Psychology, 90, 606-620. http://dx.doi.org/10.1037/0022-0663.90.4.606

[210] Pintrich, P.R. and De Groot, E.V. (1990) Motivational and Self-Regulated Learning Components of Classroom Academic Performance. Journal of Educational Psychology, 82, 33-40. http://dx.doi.org/10.1037/0022-0663.82.1.33

[211] Wentzel, K.R. (1998) Social Relationships and Motivation in Middle School: The Role of Parents, Teachers, and Peers. Journal of Educational Psychology, 90, 202-209. http://dx.doi.org/10.1037/0022-0663.90.2.202

[212] Wallace, G. (1996) Engaging with Learning. In: Rudduck, J., Chaplain, R.P. and Wallace, G., Eds., School Improvement: What Can Pupils Tell Us? London, Routledge, 52-65.

[213] Wallace, G. (1996) Relating to Teachers. In: Rudduck, J., Chaplain, R.P. and Wallace, G., Eds., School Improvement: What Can Pupils Tell Us? Routledge, London, 29-47.

[214] Brewster, C. and Fager, J. (2000) Increasing Student Engagement and Motivation: From Time-on-Task to Homework. Portland. Northwest Regional Educational Laboratory.

[215] Penna, A. and Tallerico, M. (2005) Grade Retention and School Completion through Students' Eyes. The Journal of At-Risk Issues, 11, 13-16.

[216] Willems, E.P. (1967) Sense of Obligation to High School Activities as Related to School Size and Marginality of Student. Child Development, 38, 1247-1260. http://dx.doi.org/10.2307/1127121

[217] Eccles, J.S., Wigfield, A., Midgley, C., Reuman, D., Iver, D.M. and Feldlaufer, H. (1993) Negative Effects of Traditional Middle Schools on Students' Motivation. The Elementary School Journal, 93, 553-574. http://dx.doi.org/10.1086/461740

[218] Quaglia, R.J. and Corso, M.J. (2014) Student Voice: The Instrument of Change. Corwin Press, Thousand Oaks.

[219] Epstein, J. (1981) Introduction and Overview. In: Epstein, J.L. and Jackson, P.W., Eds., The Quality of School Life, Lexington Books, Lexington, 1-17.

[220] Epstein, J. (1981) Patterns of Classroom Participation, Student Attitudes, and Achievements. In: Epstein, J.L. and Jackson, P.W., Eds., The Quality of School Life, Lexington Books, Lexington, 81-115.

[221] Piccolo, R.F., Greenbaum, R., Hartog, D.N. and Folger, R. (2010) The Relationship between Ethical Leadership and Core Job Characteristics. Journal of Organizational Behavior, 31, 259-278. http://dx.doi.org/10.1002/job.627

[222] Roeser, R.W., Midgley, C. and Urdan, T.C. (1996) Perceptions of the School Psychological Environment and Early Adolescents' Psychological and Behavioral Functioning in School: The Mediating Role of Goals and Belonging. Journal of Educational Psychology, 88, 408. http://dx.doi.org/10.1037/0022-0663.88.3.408

[223] Ryan, A.M. (2000) Peer Groups as a Context for the Socialization of Adolescents' Motivation, Engagement, and Achievement in School. Educational Psychologist, 35, 101-111. http://dx.doi.org/10.1207/S15326985EP3502_4

[224] Hamilton, S.F. (1983) The Social Side of Schooling: Ecological Studies of Classrooms and Schools. The Elementary School Journal, 83, 313-334. http://dx.doi.org/10.1086/461320 
[225] May, D.R., Gilson, R.L. and Harter, L.M. (2004) The Psychological Conditions of Meaningfulness, Safety and Availability and the Engagement of the Human Spirit at Work. Journal of Occupational and Organizational Psychology, 77, 11-37. http://dx.doi.org/10.1348/096317904322915892

[226] Harter, J.K., Schmidt, F.L. and Keyes, C.L. (2003) Well-Being in the Workplace and Its Relationship to Business Outcomes: A Review of the Gallup Studies. In: Keyes, C.L.M. and Haidt, J., Eds., Flourishing: Positive Psychology and the Life Well-Lived, American Psychological Association, Washington DC, 205-224. http://dx.doi.org/10.1037/10594-009

[227] Datnow, A., Park, V. and Kennedy, B. (2008) Acting on Data: How Urban High Schools Use Data to Improve Instruction. Center on Educational Governance, Los Angeles.

[228] Mayer, D.M., Kuenzi, M., Greenbaum, R., Bardes, M. and Salvador, R.B. (2009) How Low Does Ethical Leadership Flow? Test of a Trickle-Down Model. Organizational Behavior and Human Decision Processes, 108, 1-13. http://dx.doi.org/10.1016/j.obhdp.2008.04.002

[229] Taylor-Dunlop, K. and Norton, M.M. (1997) Out of the Mouths of Babes: Voices of At-Risk Adolescents. The Clearing House: A Journal of Educational Strategies, Issues and Ideas, 70, 274-278. http://dx.doi.org/10.1080/00098655.1997.10543935

[230] Dahl, K.L. (1995) Challenges in Understanding the Learner’s Perspective. Theory into Practice, 34, 124-130. http://dx.doi.org/10.1080/00405849509543669

[231] Newmann, F.M. (1989) Student Engagement and High School Reform. Educational Leadership, 46, 34-36.

[232] Li, Y., Lynch, A.D., Kalvin, C., Liu, J. and Lerner, R.M. (2011) Peer Relationships as a Context for the Development of School Engagement during Early Adolescence. International Journal of Behavioral Development, 35, 329-342. http://dx.doi.org/10.1177/0165025411402578

[233] Lodge, C. (2005) From Hearing Voices to Engaging in Dialogue: Problematising Student Participation in School Improvement. Journal of Educational Change, 6, 125-146. http://dx.doi.org/10.1007/s10833-005-1299-3

[234] Kohl, H.R. (1994) I Won’t Learn from You. New Press, New York.

[235] Moos, R.H. and Moos, B.S. (1978) Classroom Social Climate and Student Absences and Grades. Journal of Educational Psychology, 70, 263-269. http://dx.doi.org/10.1037/0022-0663.70.2.263

[236] Bryk, A.S., Sebring, P.B., Allensworth, E., Luppescu, S. and Easton, J. (2010) Organizing Schools for Improvement: Lessons from Chicago. University of Chicago Press, Chicago.

[237] Ma, X. and Klinger, D. (2000) Hierarchical Linear Modelling of Student and School Effects on Academic Achievement. Canadian Journal of Education, 25, 41-55. http://dx.doi.org/10.2307/1585867

[238] Demaray, M.K. and Malecki, C.K. (2002) Critical Levels of Perceived Social Support Associated with Student Adjustment. School Psychology Quarterly, 17, 213-214. http://dx.doi.org/10.1521/scpq.17.3.213.20883

[239] Osterman, K.F. (2000) Students' Need for Belonging in the School Community. Review of Educational Research, 70, 323-367. http://dx.doi.org/10.3102/00346543070003323

[240] Stanton-Salazar, R.D. (1997) A Social Capital Framework for Understanding the Socialization of Racial Minority Children and Youths. Harvard Educational Review, 67, 1-41. http://dx.doi.org/10.17763/haer.67.1.140676g74018u73k

[241] Morgan, W. and Streb, M. (2001) Building Citizenship: How Quality Service Learning Develops Civic Values. Social Science Quarterly, 82, 154-169. http://dx.doi.org/10.1111/0038-4941.00014

[242] Smyth, J. (2006) Educational Leadership That Fosters “Student Voice.” International Journal of Leadership in Education, 9, 279-284. http://dx.doi.org/10.1080/13603120600894216

[243] McLean-Donaldson, K.B. (1994) Through Students’ Eyes. Multicultural Education, 2, 26-28.

[244] Wentzel, K.R. (1997) Student Motivation in Middle School: The Role of Perceived Pedagogical Caring. Journal of Educational Psychology, 89, 411-419. http://dx.doi.org/10.1037/0022-0663.89.3.411

[245] Tyson, K. (2002) Weighing in: Elementary-Age Students and the Debate on Attitudes toward School among Black Students. Social Forces, 80, 1157-1189. http://dx.doi.org/10.1353/sof.2002.0035

[246] Goldstein, L.S. (1999) The Relational Zone: The Role of Caring Relationships in the Co-Construction of Mind. American Educational Research Journal, 36, 647-673. http://dx.doi.org/10.3102/00028312036003647

[247] Wilson, B.L. and Corbett, H.D. (2001) Listening to Urban Kids: School Reform and the Teachers They Want. SUNY Press, New York.

[248] Laffey, J. (1982) The Assessment of Involvement with School Work among Urban High School Students. Journal of Educational Psychology, 74, 62-71. http://dx.doi.org/10.1037/0022-0663.74.1.62

[249] Mahoney, J.L. and Cairns, R.B. (1997) Do Extracurricular Activities Protect against Early School Dropout? Developmental Psychology, 33, 241-253. http://dx.doi.org/10.1037/0012-1649.33.2.241 
[250] Mitra, D.L. and Gross, S.J. (2009) Increasing Student Voice in High School Reform: Building Partnerships, Improving Outcomes. Educational Management Administration \& Leadership, 37, 522-543. http://dx.doi.org/10.1177/1741143209334577

[251] Richert, A. (1994) The Corrosion of Care in the Context of School. In: Benner, P. and Bella, R., Eds., The Crisis of Care: Affirming and Restoring Caring Practices in the Helping Professions, Georgetown University Press, Washington DC, 109-118.

[252] Stinchcombe, A.L. (1964) Rebellion in a High School. Quadrangle Books, Chicago.

[253] Levin, B. (2000) Putting Students at the Centre in Education Reform. Journal of Educational Change, 1, 155-172. http://dx.doi.org/10.1023/A:1010024225888

[254] Arnot, M., McIntyre, D., Pedder, D. and Reay, D. (2004) Consultation in the Classroom: Developing Dialogue about Teaching and Learning. Pearson Publishing, Cambridge.

[255] Bragg, S. (2007) “It’s Not about Systems, It’s about Relationships”: Building a Listening Culture in a Primary School. In: Thiessen, D. and Cook-Sather, A., Eds., International Handbook of Student Experience in Elementary and Secondary School, Springer. Dordrecht, 659-680. http://dx.doi.org/10.1007/1-4020-3367-2_26

[256] Fielding, M. (2004) "New Wave” Student Voice and the Renewal of Civic Society. London Review of Education, 2, 197-217. http://dx.doi.org/10.1080/1474846042000302834

[257] Fielding, M. (2004) Transformative Approaches to Student Voice: Theoretical Underpinnings, Recalcitrant Realities. British Educational Research Journal, 30, 295-311. http://dx.doi.org/10.1080/0141192042000195236

[258] Wallerstein, N. and Bernstein, E. (1988) Empowerment Education: Freire's Ideas Adapted to Health Education. Health Education \& Behavior, 15, 379-394. http://dx.doi.org/10.1177/109019818801500402

[259] Frost, P.J. (2003) Toxic Emotions at Work: How Compassionate Managers Handle Pain and Conflict. Harvard Business Press.

[260] Moos, R.H. (1978) A Typology of Junior High and High School Classrooms. American Educational Research Journal, 15, 53-66. http://dx.doi.org/10.3102/00028312015001053

[261] Moos, R.H. (1979) Evaluating Educational Environments. Jossey-Bass, San Francisco.

[262] Trickett, E.J. and Moos, R.H. (1974) Personal Correlates of Contrasting Environments: Student Satisfactions in High School Classrooms. American Journal of Community Psychology, 2, 1-12. http://dx.doi.org/10.1007/BF00894149

[263] Miron, L.F. and Lauria, M. (1998) Student Voice as Agency: Resistance and Accommodation in Inner-City Schools. Anthropology \& Education Quarterly, 29, 189-213. http://dx.doi.org/10.1525/aeq.1998.29.2.189

[264] Marquez-Zenkov, K. (2007) Through City Students’ Eyes: Urban Students’ Beliefs about School’s Purposes, Supports, and Impediments. Visual Studies, 22, 138-154. http://dx.doi.org/10.1080/14725860701507099

[265] Howard, T.C. (2001) Telling Their Side of the Story: African-American Students’ Perceptions of Culturally Relevant Teaching. The Urban Review, 33, 131-149. http://dx.doi.org/10.1023/A:1010393224120

[266] Fehr, R. and Gelfand, M.J. (2012) The Forgiving Organization: A Multilevel Model of Forgiveness at Work. Academy of Management Review, 37, 664-688. http://dx.doi.org/10.5465/amr.2010.0497

[267] Leroy, H., Palanski, M.E. and Simons, T. (2012) Authentic Leadership and Behavioral Integrity as Drivers of Follower Commitment and Performance. Journal of Business Ethics, 107, 255-264. http://dx.doi.org/10.1007/s10551-011-1036-1

[268] Peterson, S.J., Galvin, B.M. and Lange, D. (2012) CEO Servant Leadership: Exploring Executive Characteristics and Firm Performance. Personnel Psychology, 65, 565-596. http://dx.doi.org/10.1111/j.1744-6570.2012.01253.x

[269] Lawrence, T.B. and Maitlis, S. (2012) Care and Possibility: Enacting an Ethic of Care through Narrative Practice. Academy of Management Review, 37, 641-663. http://dx.doi.org/10.5465/amr.2010.0466

[270] Walberg, H.J. and Anderson, G.J. (1968) Classroom Climate and Individual Learning. Journal of Educational Psychology, 59, 414-419. http://dx.doi.org/10.1037/h0026490

[271] Howard, T.C. (2002) Hearing Footsteps in the Dark: African American Students' Descriptions of Effective Teachers. Journal of Education for Students Placed at Risk, 7, 425-444. http://dx.doi.org/10.1207/S15327671ESPR0704_4

[272] Ferch, S.R. and Mitchell, M.M. (2001) Intentional Forgiveness in Relational Leadership: A Technique for Enhancing Effective Leadership. Journal of Leadership \& Organizational Studies, 7, 70-83. http://dx.doi.org/10.1177/107179190100700406

[273] Wright, S. and Cowen, E. (1982) Student Perception of School Environment and Its Relationship to Mood, Achievement, Popularity, and Adjustment. American Journal of Community Psychology, 10, 687-703. http://dx.doi.org/10.1007/BF01312599

[274] Zanger, V.V. (1993) Academic Costs of Social Marginalization: An Analysis of Latino Students’ Perceptions at a 
Boston High School. In: Rivera and Nieto, Eds., The Education of Latino Students in Massachusetts: Issues, Research and Policy Implications, Massachusetts University, Boston, 170-190.

[275] Mayer, D.M., Aquino, K., Greenbaum, R.L. and Kuenzi, M. (2012) Who Displays Ethical Leadership, and Why Does It Matter? An Examination of Antecedents and Consequences of Ethical Leadership. Academy of Management Journal, 55, 151-171. http://dx.doi.org/10.5465/amj.2008.0276

[276] Walumbwa, F.O., Avolio, B.J., Gardner, W.L., Wernsing, T.S. and Peterson, S.J. (2008) Authentic Leadership: Development and Validation of a Theory-Based Measure. Journal of Management, 34, 89-126. http://dx.doi.org/10.1177/0149206307308913

[277] Lennick, D. and Kiel, F. (2007) Moral Intelligence: Enhancing Business Performance and Leadership Success. Pearson Prentice Hall.

[278] Lilius, J.M., Worline, M.C., Maitlis, S., Kanov, J., Dutton, J.E. and Frost, P. (2008) The Contours and Consequences of Compassion at Work. Journal of Organizational Behavior, 29, 193-218. http://dx.doi.org/10.1002/job.508

[279] Nussbaum, M. (1996) Compassion: The Basic Social Emotion. Social Philosophy and Policy, 13, 27-58. http://dx.doi.org/10.1017/S0265052500001515

[280] Dutton, J.E., Worline, M.C., Frost, P.J. and Lilius, J. (2006) Explaining Compassion Organizing. Administrative Science Quarterly, 51, 59-96.

[281] Alvermann, D.E., Young, J.P., Weaver, D., Hinchman, K.A., Moore, D.W., Phelps, S.F. and Zalewski, P. (1996) Middle and High School Students' Perceptions of How They Experience Text-Based Discussions: A Multicase Study. Reading Research Quarterly, 31, 244-267. http://dx.doi.org/10.1598/RRQ.31.3.2

[282] Rauner, D. (2000) They Still Pick Me up When I Fall: The Role of Caring in Youth Development and Community Life. Columbia University Press, New York.

[283] Moos, R.H. and David, T.G. (1981) Evaluating and Changing Classroom Settings. In: Epstein, J.L. and Jackson, P.W., Eds., The Quality of School Life, Lexington Books, Lexington, 59-80.

[284] Midgley, C., Feldlaufer, H. and Eccles, J.S. (1989) Student/Teacher Relations and Attitudes toward Mathematics before and after the Transition to Junior High School. Child Development, 60, 981-992. http://dx.doi.org/10.2307/1131038

[285] Podsakoff, N.P., Whiting, S.W., Podsakoff, P.M. and Blume, B.D. (2009) Individual- and Organizational-Level Consequences of Organizational Citizenship Behaviors: A Meta-Analysis. Journal of Applied Psychology, 94, 122. http://dx.doi.org/10.1037/a0013079

[286] Johns, G. (2006) The Essential Impact of Context on Organizational Behavior. Academy of Management Review, 31, 386-408. http://dx.doi.org/10.5465/AMR.2006.20208687

[287] Larkin, R.W. (1979) Suburban Youth in Cultural Crisis. Oxford University Press, New York.

[288] Grimshaw, J. (1986) Philosophy and Feminist Thinking. University of Minnesota Press, Minneapolis.

[289] Sernak, K. (1998) School Leadership—Balancing Power with Caring. Teachers College Press, Williston.

[290] Rynes, S.L., Bartunek, J.M., Dutton, J.E. and Margolis, J.D. (2012) Care and Compassion through an Organizational Lens: Opening up New Possibilities. Academy of Management Review, 37, 503-523.

[291] Rogers, C. (1961) On Becoming a Person: A Therapist's View of Psychotherapy. Houghton Mifflin Company, Boston.

[292] Regan, H.B. and Brooks, G.H. (1995) Out of Women's Experience: Creating Relational Leadership. ERIC. http://eric.ed.gov/?id=ED386808

[293] Senge, P.M. (1997) The Fifth Discipline. Measuring Business Excellence, 1, 46-51. http://dx.doi.org/10.1108/eb025496

[294] Wuthnow, R. (1991) Acts of Compassion: Caring for Others and Helping Ourselves. Princeton University Press, Princeton.

[295] Liedtka, J.M. (1996) Feminist Morality and Competitive Reality: A Role for an Ethic of Care? Business Ethics Quarterly, 6, 179-200. http://dx.doi.org/10.2307/3857622

[296] Madden, L.T., Duchon, D., Madden, T.M. and Plowman, D.A. (2012) Emergent Organizational Capacity for Compassion. Academy of Management Review, 37, 689-708. http://dx.doi.org/10.5465/amr.2010.0424

[297] Sernak, K.S. (2004) Slaves No More: The Caring Power of African-American Female Leaders. Scholar-Practitioner Quarterly, 2, 71-97.

[298] Marshall, C., Patterson, J.A., Rogers, D.L. and Steele, J.R. (1996) Caring as Career: An Alternative Perspective for Educational Administration. Educational Administration Quarterly, 32, 271-294. http://dx.doi.org/10.1177/0013161X96032002005 
[299] Solomon, R.C. (1998) The Moral Psychology of Business: Care and Compassion in the Corporation. Business Ethics Quarterly, 8, 515-533. http://dx.doi.org/10.2307/3857435

[300] Cameron, K.S., Dutton, J.E. and Quinn, R.E. (2003) Positive Organizational Scholarship: Foundations of a New Discipline. Berrett-Koehler, San Francisco.

[301] Snyder, C.R. and Lopez, S.J. (2009) Oxford Handbooks of Positive Psychology. Oxford Press, New York.

[302] Glynn, M. and Jamerson, H. (2006) Principled Leadership: A Framework for Action. In: Hess and Cameron, K.S., Eds., Leading Values: Positivity, Virtue, and High Performance, 151-171. http://dx.doi.org/10.1017/cbo9780511753770.009

\section{Submit or recommend next manuscript to SCIRP and we will provide best service for you:}

Accepting pre-submission inquiries through Email, Facebook, LinkedIn, Twitter, etc.

A wide selection of journals (inclusive of 9 subjects, more than 200 journals)

Providing 24-hour high-quality service

User-friendly online submission system

Fair and swift peer-review system

Efficient typesetting and proofreading procedure

Display of the result of downloads and visits, as well as the number of cited articles

Maximum dissemination of your research work

Submit your manuscript at: http://papersubmission.scirp.org/

Or contact jhrss@scirp.org 